OECDpublishing

\title{
THE EVOLVING ROLE
}

OF SATELLITE

NETWORKS IN RURAL

AND REMOTE

BROADBAND ACCESS

OECD DIGITAL ECONOMY PAPERS

December 2017 No. 264 


\section{FOREWORD}

This report was prepared by the Working Party on Communication Infrastructure and Services Policy (WPCISP). It provides information and discussion on the emerging technologies in the satellite industry and considers the potential of these innovations and the role of satellites in delivering broadband to residential customers.

This paper was approved and declassified by written procedure by the Committee on Digital Economy Policy in May 2017 and prepared for publication by the OECD Secretariat.

The document was drafted by Dr. David Reed, Director of the Interdisciplinary Telecommunications Program at the University of Colorado at Boulder and Lauren Crean from the OECD Secretariat at that time. Further contributions were provided by Alexia Lee González Fanfalone, Verena Weber, Yuki Yokomori and Sam Paltridge, all from the OECD Secretariat. The work was further supported by written contributions from Brazil, Canada, Egypt, Italy, Mexico, Russia, Switzerland, the United Kingdom, and the United States as well as from AT\&T, Eutelsat, and O3b.

\section{Note to Delegations:}

This document is also available on O.N.E. Members and Partners under the reference code: DSTI/CDEP/CISP(2016)5/FINAL

This document and any map included herein are without prejudice to the status of or sovereignty over any territory, to the delimitation of international frontiers and boundaries and to the name of any territory, city or area.

The statistical data for Israel are supplied by and under the responsibility of the relevant Israeli authorities. The use of such data by the OECD is without prejudice to the status of the Golan Heights, East Jerusalem and Israeli settlements in the West Bank under the terms of international law.

(C) OECD 2017

You can copy, download or print OECD content for your own use, and you can include excerpts from OECD publications, databases and multimedia products in your own documents, presentations, blogs, websites and teaching materials, provided that suitable acknowledgment of OECD as source and copyright owner is given. All requests for commercial use and translation rights should be submitted to rights@oecd.org. 


\title{
THE EVOLVING ROLE OF SATELLITE NETWORKS IN RURAL AND REMOTE BROADBAND ACCESS
}

\begin{abstract}
Satellites serve as an important option to deliver broadband services to residences and businesses in rural and remote regions throughout the world. In OECD countries, the majority of people live in urban areas or at locations that are closely settled enough to use other broadband access technologies on a cost effective basis. The satellite industry, however, is introducing several significant innovations that result in improved capabilities and may substantially change the costs of providing broadband services. The purpose of this report is to describe these key recent developments based upon new and anticipated satellite broadband deployments, and discuss their implications for the future use of satellites to deliver broadband services to residential and business users. In short, the report investigates how innovation is changing the role of satellites in extending broadband services to underserved areas in relation to other terrestrial broadband options. With the changing role of satellite in the provision of broadband service, and in anticipation of new broadband satellite systems, there are important policy challenges to be considered. These include evaluating the role of government subsidy programmes, and considering how to address regulatory hurdles to enable development and deployment of competitive new technologies.
\end{abstract}


TABLE OF CONTENTS

THE EVOLVING ROLE OF SATELLITE NETWORKS IN RURAL AND REMOTE BROADBAND

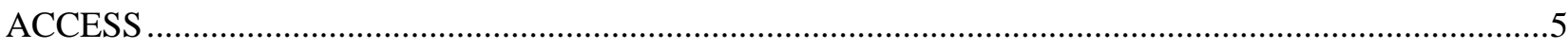

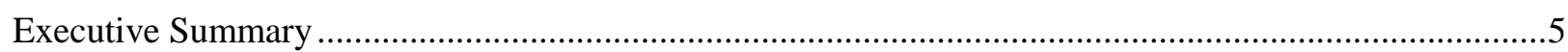

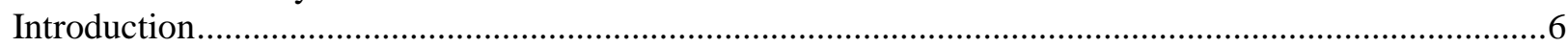

OVERVIEW OF CURRENT BROADBAND SATELLITE SERVICES …................................................

Pricing and Speed in the Current Satellite Broadband Market .................................................................

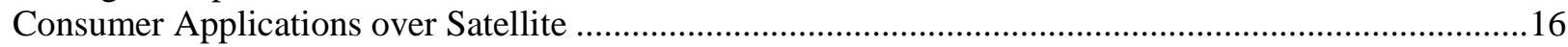

Key Trends in Broadband Satellite Systems ........................................................................................17

Introduction to Low (LEO) and Medium Earth Orbit (MEO) Satellite Systems ..................................18

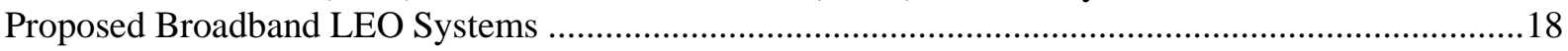

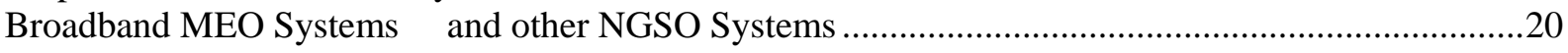

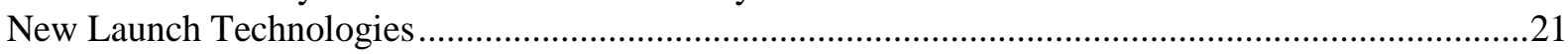

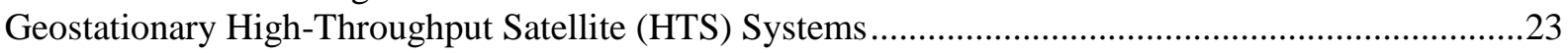

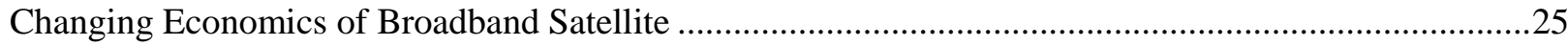

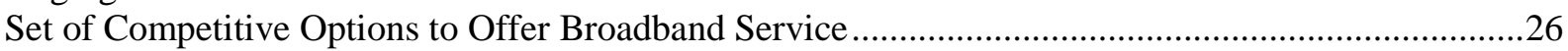

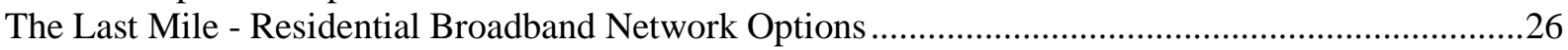

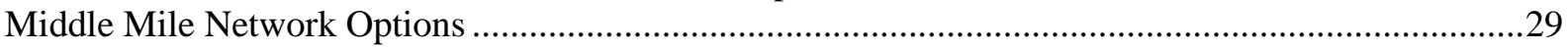

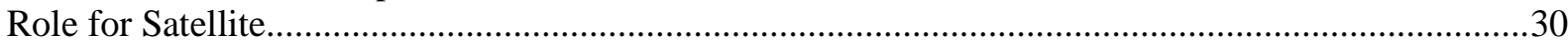

Developing Policies for Broadband Satellite Systems ...........................................................................33

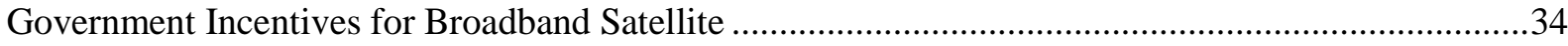

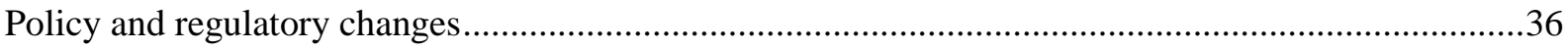

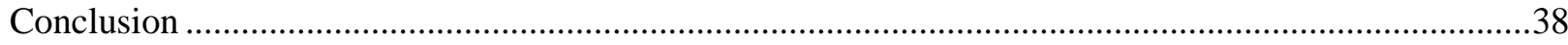

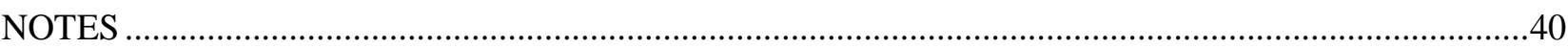

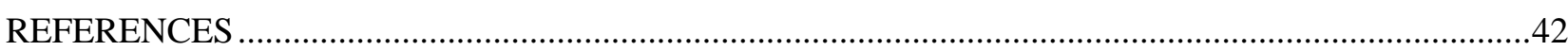




\section{THE EVOLVING ROLE OF SATELLITE NETWORKS IN RURAL AND REMOTE BROADBAND ACCESS}

\section{Executive Summary}

Satellites serve as an important option to deliver broadband services to residences and businesses in rural and remote regions throughout the world. In OECD countries, the majority of people live in urban areas or at locations that are closely settled enough to use other broadband access technologies on a cost effective basis. The satellite industry, however, is introducing several significant innovations that result in improved capabilities and may substantially change the costs of providing broadband services. The purpose of this report is to describe these key developments based upon new and anticipated satellite broadband deployments, and discuss their implications for the future use of satellites to deliver broadband services to residential and business users. In short, the report investigates how innovation is changing the role of satellites in extending broadband services to underserved areas in relation to other terrestrial broadband options.

Today, most broadband satellite services offered in OECD and partner countries are differentiated by daily and monthly data allowances, and less often by speed as is common on terrestrial networks. Using networks that are shared amongst a large number of users, satellite providers may impose strict Fair Use Policy statements to closely manage congestion based upon these usage allowances. Prices of satellite broadband service today reflect wide variation across countries with an average of USD 5.64 Purchasing Power Parity (PPP) per GB at peak times and USD 5.39 PPP per GB when including off-peak times over the selected regions included in this study. The prices per GB were lower for plans with data allowances between 25 GB and 50 GB than for those between 1 GB and 10 GB, reflecting lower per GB rates for higher volumes. While advertised and actual speeds for satellites are increasing, there are still some limitations due to the nature of the technology.

Usage-based pricing over limited capacity reduces consumers' use of streaming video applications, while latency may limit the use of highly interactive real-time applications, as compared to terrestrial broadband networks. Innovations designed to address these limitations of network capacity and network latency are being incorporated into new satellite systems and are described in the report. First, because the height of orbit for the satellite above the Earth's surface has a significant effect on system cost and types of services delivered, a number of new Low-Earth Orbit (LEO) and Medium-Earth Orbit (MEO) systems have been proposed or deployed to provide satellite broadband services. The resulting power savings and latency reductions can significantly reduce satellite equipment costs on the user's premises, and allow for a much higher quality of experience associated with real-time services such as multi-player gaming services, Voice over Internet Protocol (VoIP) calls and video chat. Second, while LEO and MEO systems require more satellites to cover a large area given their lower altitude, new technologies such as reusable launch vehicles and electric propulsion systems are leading to lower cost satellite launch systems. Third, geostationary (GEO) high-throughput satellite (HTS) systems are being launched regularly which use multiple spot beams to significantly increase the throughput of the satellite system. The report describes several new HTS systems that have been recently deployed with substantial capacity to deliver broadband services. 
Given these innovations, the report examines how the changing economics of broadband satellite services are leading to new roles for satellite technology in the delivery of residential and "middle mile" broadband services. The report identifies three different roles for satellite systems going forward: i) filling the coverage gap to deliver broadband service to remote and isolated geographic areas by offering ubiquitous and easy to deploy solutions; ii) providing a middle mile solution connecting mobile and fixed wireless local access networks to nationwide or global core networks; and iii) potentially expanding the market for satellite broadband through the use of LEO satellites to deliver broadband to lower density areas closely adjoining urban areas. Where a fibre backbone network has been widely deployed, then the cost of a short distance fibre- or microwave-based middle mile solution may be more attractive.

With the changing role of satellite in the provision of broadband service, and in anticipation of new broadband satellite systems, there are important policy challenges to be considered. These include evaluating the role of government subsidy programmes, and considering how to address regulatory hurdles to enable development and deployment of competitive new technologies.

\section{Introduction}

For more than two decades, satellites have been used to deliver high-speed data communication services to geographical areas that are hard to reach with other modern telecommunication infrastructure and to provide network resiliency. As the Internet has emerged as an essential information service over the same time period, satellites are often the best option for providing broadband transport to higher cost areas, which are currently under or unserved. The industry generates approximately USD 18 to USD 22 billion annually for satellite operators, (OECD, 2016a). In OECD countries, satellite broadband penetration rates average 0.2 subscriptions per 100 inhabitants, as of December 2015. The United States holds the highest subscription rate of 0.7 per 100 inhabitants. Ireland, New Zealand and the United States are the only three OECD members who report subscription rates above 0.1 per 100 inhabitants (OECD, 2016b). ${ }^{1}$

The purpose of this report is to describe key recent developments and future trends for the use of satellites to deliver Internet access or broadband services in rural and remote areas throughout the world. Pursuant to that objective, the report aims to identify both the key emerging technological innovations in modern broadband satellite networks that are driving significant changes in the economics of satellite networks and the overall role of this technology as one of the options to deliver broadband services to residences and businesses. The report considers how these innovations are affecting the role of satellites in extending broadband services to underserved areas as well as whether the new broadband nongeostationary satellites (whether LEO or MEO) and GEO HTS satellite systems will be a complement or competitor to fixed and terrestrial mobile broadband services in the future.

The report focuses on the use of satellites to deliver broadband services to residential and business users ("last mile") and also to telecommunication service providers ("middle mile"). "Last mile" refers to satellite-based technology and systems needed to provide high-speed Internet access to residential consumers in a fixed "Direct-to-Home" (DTH) model through the use of a satellite receiver dish or terminal on the consumer's premise. "Middle mile" refers to the use of satellites to provide backhaul or backbone network interconnection to the global Internet for terrestrial fixed or mobile telecommunication network service providers, including mobile network operators (MNOs) and Internet service providers (ISPs). These networks are in geographically dispersed communities and regions. The report does not consider issues such as how satellites can be used to support mobility services for maritime, aeronautical or public safety applications.

This report is organised as follows. Section 1 begins with a survey of the current broadband satellite services offered today in terms of price and usage allowances by service providers in OECD member and key partner countries for broadband satellite services. Section 2 describes the modern, state-of-the-art 
satellite broadband systems, and the major new technology trends that are significantly changing how the next generation of broadband satellite systems will be built and deployed. Section 3 discusses the new economics of broadband satellite systems and the changing role of satellite systems in the overall broadband ecosystem caused by these new technological innovations. Section 4 concludes with a discussion of the development of policies to enable further development of new satellite broadband systems.

The report includes many different case studies of how satellites systems currently are being built, deployed or regulated. These written contributions in the report have been provided by OECD countries and selected countries as well as equipment suppliers as noted and provide rich context for the current status of broadband satellite deployments and their role in the broadband plans of the respective governments. 


\section{OVERVIEW OF CURRENT BROADBAND SATELLITE SERVICES}

Broadband services over satellite have frequently targeted rural and remote areas, which are under- or unserved by terrestrial options. Given the fact that they are usually sparsely populated, many terrestrial providers may not build out infrastructure to support the few households living in the area, making satellite broadband an attractive alternative. Sometimes, even sparsely populated areas close to metropolitan areas face similar problems despite being located just a few kilometres from a well-connected city. These areas present an emerging market for satellite broadband services (Peterson, 2015). There are generally two ways in which satellite is used to deliver Internet services to consumers. The most common approach is the 'direct-to-home' (DTH) model, where service is provided directly to an end user via an antenna or terminal installed on the customer premise. The DTH approach is the model used by European providers such as Europasat, RBSat and Avonline Broadband, and North American providers such as ViaSat and Xplornet, as well as Hughes, who provides service in both North and South America, to directly service residential and enterprise broadband users.

Another common method by which satellites are used to deliver Internet to households is the 'community aggregator' model. In this model, the backhaul connection is made via satellite to an earth station and then transmitted to households, enterprises and institutions through either fixed or mobile terrestrial networks. This backhaul model is often used in communities that are very remote or where the local population distribution is still compact. For example, there are nearly 100 communities entirely reliant on satellite using this model in Canada, the majority of which are in the eastern Arctic (CRTC, 2014). ${ }^{2}$

This section provides a summary of the characteristics of satellite-based residential broadband services deployed today based primarily on the DTH model in OECD member and key partner countries. The report first presents the common elements and significant differences between current DTH service packages around the world. The report then discusses what is known regarding the different types of Internet applications that are used by residential consumers of satellite broadband services.

\section{Pricing and Speed in the Current Satellite Broadband Market}

The report begins by describing current broadband service plans using satellite networks in OECD and key partner countries. It is based on publically available pricing information on satellite broadband offers for residential broadband service in selected countries. For means of comparison, the advertised prices were converted to the purchasing power parity (PPP) in USD as of 2015, unless otherwise indicated. The countries included in the survey were categorised into four regions: i) Asia and Pacific represented by Australia, Indonesia, Japan, and Korea; ii) South America made up of Brazil, Chile, and Colombia; iii) North America comprised of Canada, Mexico, and the United States; and iv) Europe represented by Austria, Denmark, France, Germany, Ireland, Portugal, Spain, Sweden, Turkey, and the United Kingdom.

Analysis of the market data reveals three commonalities based upon a comparison of existing satellite broadband pricing plans and packages. These can be generalised as follows:

- Offers are usually differentiated by data allowance, and less often by speed.

- Fair Use Policies are put in place to manage congestion. 
- $\quad$ Start-up fees may be considerable, but the amount varies greatly by region.

The first trend viewed across providers is that offers are usually differentiated by daily and/or monthly data allowances using usage-based billing plans. The basic structure is to offer consumers several different plans with varying data allowances with the same speed, though this may change in the future as speeds increase with newer technology. To manage traffic on the shared network, satellite providers define and measure usage over a specified period of time (usually daily and/or monthly) and restrict the amount of data usage per consumer. The analysis of current satellite plans shows how the monthly fee increases as the data allowance increases (Figure 1). The trend line for this rate of increase is roughly equivalent to USD 2.50 PPP per additional GigaByte (GB) in the peak period.

Figure 1. Data allowance by monthly pricing plan

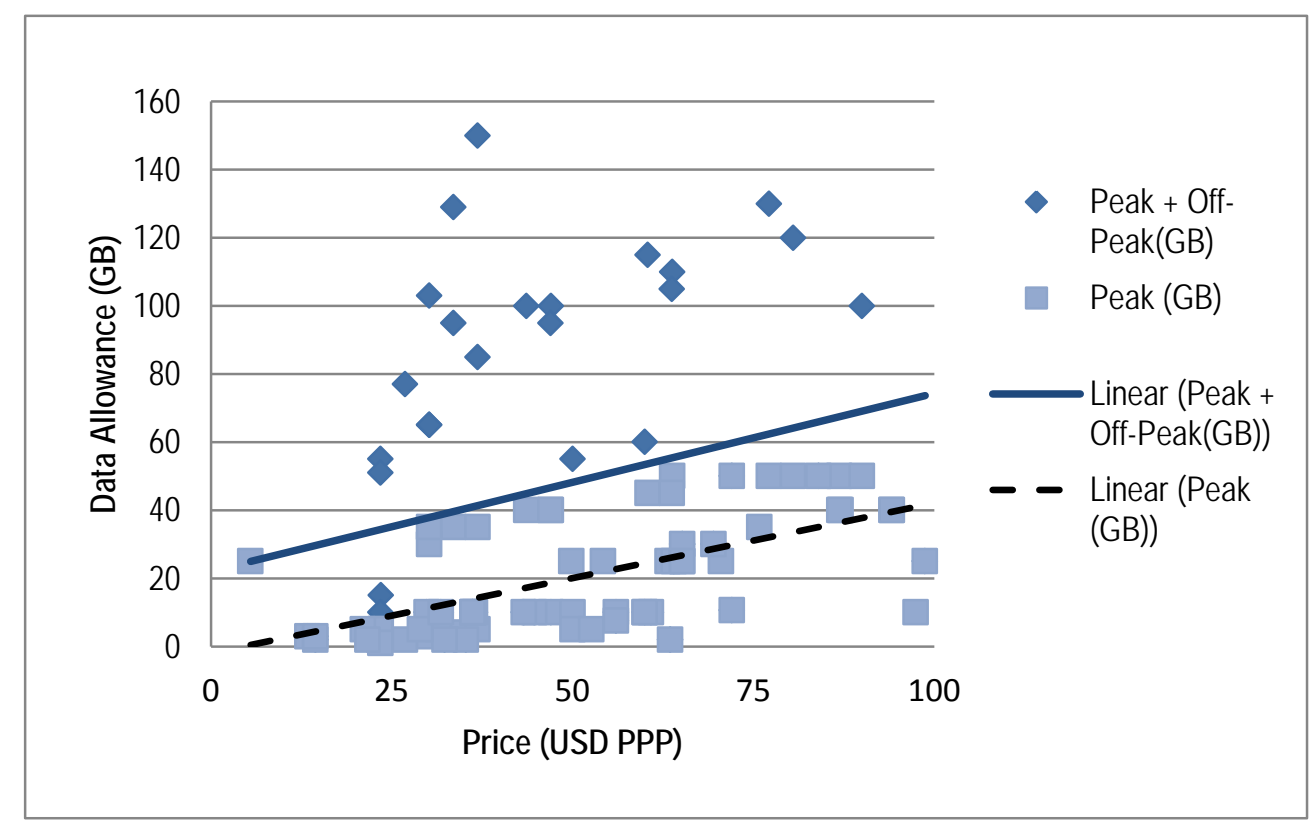

Note: The sample consisted of plans with a monthly price of under USD 100 PPP and excluded unlimited data plans for means of analysis and comparison.

Source: Company websites.

When considering speed per additional USD, many data points fall in a horizontal line, indicating that no matter the price of the plan, the speeds remain the same (Figure 2). For example, France's Europasat service plans vary between $3-20$ GB at the same speed of 20/2 Mbps. Australia's Activ8me service offers several plans with monthly allowances varying from 5 - 50 Gigabyte (GB), each with download/upload speed options of 12/1 Mbps or 25/5 Mbps. However, SkyDSL is a notable example which offers unlimited data plans to end customers. Other providers like Germany's Orbitcom or Brazil's Via Sat, for example, vary both the speeds and data allowances in their offers. Overall, download speeds for residential customers $^{3}$ across providers commonly range between 1 Mbps and $25 \mathrm{Mbps}$, and upload speeds between 0.5 Mbps and 6 Mbps. This corresponds to download and upload speed prices increasing roughly by USD 30 PPP per Mbps and USD 50 PPP per Mbps, respectively. 
Figure 2. Speeds by Monthly Price

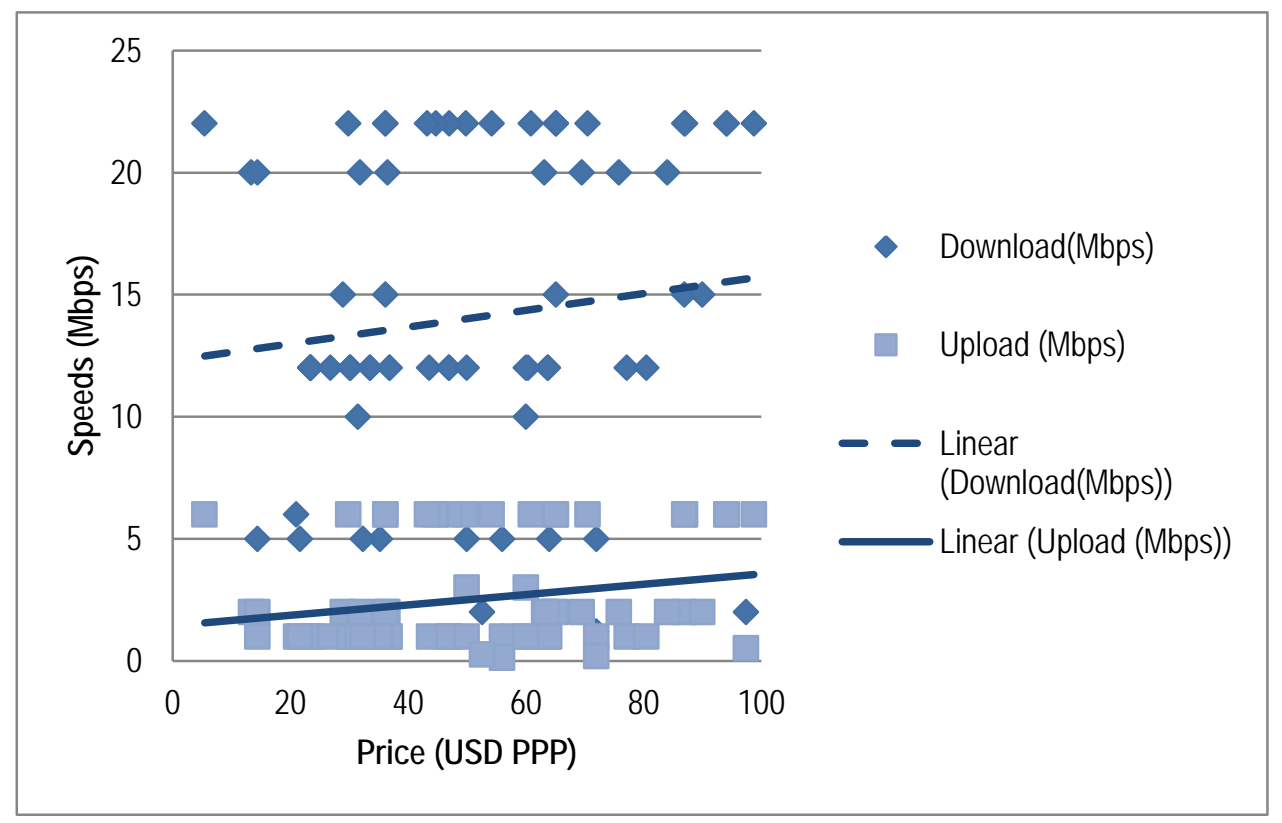

Note: The sample consisted of plans with a monthly price of under USD 100 PPP for means of analysis and comparison. Source: Company websites.

A focus on data allowances in usage-based billing plans occurs due to the potentially higher degree of shared capacity or amount of capacity "over-subscription" associated with satellite systems in comparison to both wired and wireless terrestrial networks. This creates a strong requirement to closely manage customer expectations governing network usage to ensure that the satellite capacity is not oversubscribed in order to maintain an adequate quality of experience for consumers. Data allowances are the key tool available to service providers to manage network traffic in this regard based upon the pricing discipline imposed upon consumers who want to avoid overage charges. This approach to services plans is similar to terrestrial mobile service providers that have similar shared network capacity issues over their cellular networks to manage, and different from terrestrial fixed broadband providers who commonly differentiate unlimited usage plans by speed, since they are able to increase network capacity relatively quickly at a lower incremental cost.

The second common element in the service plans is the important use of a Fair Use Policy (FUP, or equivalently a Fair Access Policy (FAP)) to manage congestion over the shared satellite network platform. An FUP sets out guidelines on data usage and network management policies to ensure each customer serviced by a single satellite will have "fair" access to the satellite bandwidth. Once a user reaches the monthly data allowance, there is usually either a fee for additional usage or speeds are reduced until the monthly period is reset. As an example, Hughes has a FAP that will slow the speed of service once the monthly data allowance has been reached until the next billing period (Hughes, 2017). These policies shape consumer usage patterns and can be more restrictive than the acceptable use policies for other broadband technologies, resulting from some bandwidth limitations on satellite systems. In addition, the daily data allowance for satellite usage found in some FAPs differ from most terrestrial cellular service usage plans that allow mobile users to increase their usage towards the end of a billing cycle in the knowledge that they would otherwise have paid for unused data (Galaxy Broadband, 2017; Hughes 2017). 
Notably, some satellite broadband retailers are able to offer unlimited data plans without a FUP, regardless of the wholesale satellite network's FUPs. As briefly mentioned above, SkyDSL, who uses Eutelsat's satellite network to offer internet via satellite to many countries in Europe, acts as a Virtual Network Operator (VNO) to buy Ka-band satellite capacity on Eutelsat's network. Through this partnership, SkyDSL is able to decide how to package and offer their service to their end customers, meaning that it can offer unlimited data plans without a FUP, with the only parameter determined by Eutelsat being the speed that can be offered (Eutelsat, 2016). This differs from Eutelsat's Tooway brand, whose speed, data allowance, FUP, and price points are set by Eutelsat and then sold to customers by smaller distributors, such as Europasat (Tooway, 2016).

Satellite providers FUPs frequently offer ways to encourage customers to alter their usage patterns to off-peak periods given the limitations on the available network capacity. For example, Australia's SkyMesh offers "Night Owl" plans, which give a higher data allowance to users who can use the majority of their data during off-peak times (between 1am - 7am for this plan) and a lower allowance during peak times. Other satellite providers market the off-peak period to provide "bonus" data, or in some cases, unlimited data during the early hours of a day, such as Hughes' "bonus zone” which allows customers to use data between 2am-8am without counting towards their monthly data allowance (Hughes, 2017). Alternative strategies include differing both speed and data allowance for a given price point such as for Australia’s National Broadband Network (NBN) plans (Box 1).

The third element, common to many broadband service providers across technologies, is that almost all plans include start-up costs. In this sense, broadband satellite service plans typically include one or all of the following: installation fees, activation fees, equipment purchase or rental fees, or licensing fees. Some providers offer special discounts to offer free installation or waive activation and licensing fees, or all-start-up costs. Australia, in contrast, was the only country surveyed whose plans had no upfront fees due to the public funding of the service, as satellite broadband is part of a larger national broadband plan to provide Internet access to rural communities. Start-up prices are higher across the board in Japan and Korea, likely reflecting less demand for satellite use in these countries except for the most remote locations given their extensive coverage by terrestrial fibre optic networks. In such circumstances providers may have high start-up fees in the knowledge of government subsidies to these households, thereby making public funding carry some of the burden of high installation costs in such locations. Ease of access and level of demand are reasons that may also be applied to the South American market, also characterised by high installation and equipment fees.

Among the companies assessed, the start-up fees usually fall within the range of USD 100 PPP to USD 300 PPP for residential users, with a few notable exceptions. For Hughes Brasil, installation costs vary based on the customer's distance from an urban area; within $30 \mathrm{~km}$ of a city there are often no installation costs, but installers may charge BRL 1.50 (approximately USD $0.82 \mathrm{PPP}$ ) for each km above $30 \mathrm{~km}$ (HughesNet Brasil, 2016). Therefore, rural and remote areas may have to pay a much higher fee for installation compared to urban or suburban areas. Japan had higher initial fees of USD 5221 PPP, as did Colombia with a charge of USD 1940 PPP though some of the prices may be primarily aimed at business users or for a community dish. Countries with lower start-up fees included Australia's zero fees, and Spain, Canada and Denmark at USD 44.70 PPP, USD 79.20 PPP, and USD 79.66 PPP respectively. Thus, it is clear that start-up costs can be considerable in a few circumstances, though there is a wide variation between companies and countries. 


\section{Box 1. Broadband satellite use in Australia: the National Broadband Network (NBN)}

As part of the NBN, Australia launched two state-of-the-art geostationary satellites in 2015 and 2016. Called "Sky Muster" the satellites cover mainland Australia and nearby islands in order to provide broadband access to areas where the use of other technologies would be cost-prohibitive. The two NBN satellites have a combined capacity of 135 Gbps with initial wholesale speed options available to retail Internet service providers of $12 \mathrm{Mbps}$ download with a $1 \mathrm{Mbps}$ upload, or $25 \mathrm{Mbps}$ download with a $5 \mathrm{Mbps}$ upload. In terms of access, speed and data allowances the new satellites represent substantial gains for users in terms of availability, cost and quality of service.

While Sky Muster has the same inherent limitations as any geostationary satellite (i.e. latency due to distance may affect some services) or potential outages at times of certain weather conditions (e.g. torrential rainfall), the main limitation compared with terrestrial technologies is always the more limited capacity available compared with demand. The main tool to manage this challenge and ensure the most efficient usage is pricing and this is evident in comparing the offers available across different NBN technologies (Table 1). Even though NBN has said it will apply 'cross subsidies', from services offered over other technologies, the differences in price for service via satellites compared to terrestrial NBN options are evident as the amount of data increases. On the other hand, as noted, the capabilities represent a major improvement on previous options (e.g. fixed wireless via $3 G$ or the previous generation of satellites) and the program carries considerable public funding costs to meet policy objectives. By way of example, for potential savings, a user moving to the NBN satellite from a 3G fixed wireless plan could pay nearly three times less for four times the data with a higher speed.

Table 1. Retail NBN prices over different technologies in Australia

\section{NBN Satellite (Activ8me)}

Monthly Peak Data

(speed at $12 \mathrm{Mbps}$ )

Monthly Off-Peak

Data (1am-7am)

Monthly Fee for 12

Mbps (USD)

Price/GB at peak

times (USD)

Price/GB overall

(USD)

$5 \mathrm{~GB}$

$15 G B$

50GB

50GB

26.46

30.24

5.29

0.48

3.79

Mbps (USD)

0.46

3.79
Additional fee for 25

\subsection{2}

250GB

37.81

Unlimited

50GB

30.24

Monthly fee, speed

0.60

7.57

Price/GB (USD)

Additional fee for 25

Mbps (USD)
0.14

7.57
40GB

60GB

49.17

1.23

0.48

3.79
45GB

70GB

68.09

1.51

0.59

3.79
50GB

80GB

87.02

1.74

0.67

3.79

\section{NBN Fixed Network (internode)}

\begin{tabular}{lrrr} 
Data included & 100GB & 500GB & \multicolumn{1}{c}{ Unlimited } \\
Speed at 12 Mbps & & & \\
Monthly fee & 37.84 & 49.20 & 52.98 \\
Price/GB (USD) & .38 & .10 & N/A \\
Speed at 25 Mbps & & & \\
Monthly fee & 41.63 & 56.77 & 60.55 \\
Price/GB (USD) & 0.42 & 0.11 & N/A \\
Speed at 50 Mbps & & & \\
Monthly fee & 49.20 & 64.34 & 68.12 \\
Price/GB (USD) & .49 & 0.13 & N/A \\
Speed at 10O Mbps & & & \\
Monthly fee & 56.77 & 71.91 & 75.69 \\
Price/GB (USD) & 0.57 & 0.14 & N/A
\end{tabular}

Note: Conversion rate of 0.757 USD= 1 AUS used, as of 3 August 2016. 
The comparison of satellite plans across countries also identified three important differences among the satellite broadband markets.

- Monthly prices of satellite broadband service reflect a wide variation between USD 13.35 PPP and USD 147.49 PPP.

- Large regional differences in satellite prices also were observed.

- The ease of obtaining service plan information was relatively easy to access via the World Wide Web in North America and Europe, but less so in other regions.

First, there were substantial differences in the prices of the satellite broadband service plans. The average price of the least expensive options offered in the countries varies widely, ranging from the lowest average of USD 13.35 PPP in France to the highest in Brazil at USD 147.49 PPP. There is also a wide variation in the speed and data allowance in a given plan, and the associated monthly price (Figures 1and 2). For comparison, the most basic Europasat bundle offered in France costs USD 13.35 PPP monthly for an advertised speed of 20 Mbps download, 2 Mbps upload and 3 GB of data (Europasat, 2016a). Conversely, a basic plan offered by Canada's Xplornet charges around USD 55.99 PPP for a lower advertised speed (5 Mbps download/ 1 Mbps upload) but a higher data allowance of 25 GB monthly (Xplornet Communications, 2016b).

These individual price differences in plans can be expected given the unique characteristics of individual markets within each country, and indeed, is seen among other broadband technologies. The prices and packages for satellite broadband are a result of the way that retailers, wholesale providers and customers interact with one another, often influenced by factors such as regulation, the generation of satellites in play, public subsidies and so forth. Satellite wholesale providers can determine the terms and conditions of how retailers must provide service to the end customer, such as the upload and download speeds as well as the usage conditions. For example, the European satellite broadband distributor Europasat interfaces with three Ka-band satellite networks, Eutelsat, Astra SES and Avanti, who support residential service throughout Europe. Europasat largely establishes the packages and pricing offered to customers, varying slightly based on location and which satellite network corresponds to that location. Subsequently, local resellers buy wholesale from Europasat, then market and sell Europasat's packages to local customers. These resellers have varying degrees of interaction with the customer, from only selling the product, to installing equipment, or even to fully managing billing and on-going support (Europasat, 2016b).

A further example of the satellite value chain can be seen in the delivery of satellite service in Switzerland. Swisscom, the country's universal service provider, contracts the use of a satellite network, then undertakes the subsequent management of the service facing the customer, though the satellite partner operates all of the connections (Box 2).

\section{Box 2. Satellite pricing and speeds in Switzerland}

Since 2008, Switzerland has introduced a universal service obligation (USO) for broadband Internet access service (IAS) to all citizens at defined speeds and subject to a price ceiling. As USO is technologically neutral, the universal service incumbent, Swisscom, must offer the minimum Internet access service (2 Mbps on the downlink and $200 \mathrm{Kbps}$ on the uplink) using a variety of different technologies depending on the land topology and available infrastructure or services. Today, some $98 \%$ of the Swiss households are provided with IAS via Digital Subscriber Line (DSL) technology and the remaining $2 \%$ are served via satellite or mobile (3G or $4 G$ ) technologies. The latest Swisscom statistics indicate that 1250 homes in Switzerland are supplied via a satellite bidirectional IAS (1 916 homes via mobile technologies) and $95 \%$ of these are situated in rural or low population density areas (statistics as of August 2016). 
The USO obliges the universal service provider to install the required satellite communications hardware in homes at no cost: an outdoor parabolic antenna, a satellite modem and an IP router to the network termination point. In this case, the universal service customer benefits from a stable Internet connection at the universal service ceiling price of CHF 59.35 per month, including a fee of CHF 25.35 for a telephone line, VAT included (USD 59.95 per month, USD 25.61 for telephone line, as of market rate on 5 October: $1 \mathrm{CHF}=1.0266$ USD). The satellite communications hardware (antenna and modem) remains the property of the universal service provider while the router becomes the property of the end user.

Swisscom does not operate its own satellite IAS but subcontracts this from SES TechCom, a fully-owned subsidiary of SES, a satellite company headquartered in Luxembourg. Swisscom then divides the total bandwidth between the 1250 customers, though the satellite partner operates all of the connections. The bandwidth allocated to every satellite recipient is up to $3 \mathrm{Mbps}$ on the downlink and $300 \mathrm{Kbps}$ on the uplink, fulfilling the minimum IAS speed specified by law (2 Mbps downlink and $200 \mathrm{Kbps}$ uplink). As a result, satellite end users often benefit from a higher bandwidth than that defined in law, which compensates for the disadvantages of satellite technology.

The Swisscom universal service satellite IAS customer satisfaction index seems to be quite high according to the latest statistics from the universal service incumbent. The yearly quality of service report, submitted by Swisscom to the Swiss regulator OFCOM, confirms these figures. The average bandwidth delivered by Swisscom over the year in 2015 using satellite technology was $2.7 \mathrm{Mbps}$ on the downlink and $257 \mathrm{Kbps}$ on the uplink, which is sufficient for simple Internet usage.

The main disadvantages of broadband via satellite are the connection delay (due to orbital distance) and the socalled "fair use policy". The bidirectional satellite links suffer from a longer delay than any other terrestrial technology, which adversely affects services such as IP telephony and video telephony. The second drawback is the "fair use policy" which sets a limit on total data consumption per month. Each universal service satellite communications subscriber is allocated $16 \mathrm{~GB}$ of data per month. If customers exceed this limit, their bandwidth is capped to $400 \mathrm{Kbps}$ on the downlink and $200 \mathrm{Kbps}$ on the uplink between 8 a.m. - 10 p.m., though with no limits outside these hours.

To further compare and understand the variation in pricing of broadband satellite service versus monthly data allowance, two example tiers of current satellite service offers were selected based on monthly data allowance size: i) offers featuring "low data plans" with limits between 1 GB and $10 \mathrm{~GB}$, and ii) offers featuring "high data plans" with limits from 25 to 50 GB. ${ }^{4}$ Two plans from each company were chosen based on their data allocations, in each of the selected countries, and were used to calculate regional and overall averages of the sample within each tier. In instances where there was more than one offer within a data tier, the lowest price/GB offer was chosen. ${ }^{5}$ Speeds of the selected service offers were not included given the potential variation in advertised and actual speeds. To illustrate the methodology, consider the plans of Europasat, Xplornet and Avonline. The three companies offer 3GB for USD 13.35 PPP, 10 GB for USD 55.99 PPP and 5 GB for USD 28.91 PPP, respectively. This provides a GB unit price for Europasat of USD 4.45 PPP per GB, USD 5.60 PPP per GB for Xplornet and USD 5.78 PPP per GB for Avonline.

Overall, the service offers were categorised into four geographic areas (Table 2). It is important to highlight that the sample for each of these areas is relatively small given the nature of the satellite market. The main purpose of this undertaking is to give a broad indication of prices by amount of data across different regions, not to compare individual providers or offers. The price per GB comparison was done using both OECD market exchange rates (USD) as well as purchasing power parity (USD PPP) to give a complete picture in pricing using both the market rate and the normalised PPP rate found among the various OECD countries. 
Table 2. Comparison of Monthly Price per 1GB for Low and High Data Plans

\begin{tabular}{|c|c|c|c|c|c|}
\hline & & $\begin{array}{ll}\text { Price per } 1 \text { GB } \\
\text { (peak } & \text { only) } \\
\text { USD PPP } & \end{array}$ & $\begin{array}{l}\text { Price per } 1 \text { GB } \\
\text { (peak +off- } \\
\text { peak) USD PPP }\end{array}$ & $\begin{array}{l}\text { Price per } 1 \\
\text { GB (peak } \\
\text { only) USD }\end{array}$ & $\begin{array}{l}\text { Price per } 1 \mathrm{~GB} \\
\text { (peak +off- } \\
\text { peak) USD }\end{array}$ \\
\hline & AVERAGE (total sample) & USD 5.64 & USD 5.39 & USD 4.66 & USD 3.95 \\
\hline & Low data plan GB Average & USD 7.38 & USD 6.83 & USD 6.34 & USD 5.83 \\
\hline & High data plan GB Average & USD 3.82 & USD 3.23 & USD 2.89 & USD 1.87 \\
\hline \multirow[t]{3}{*}{ Asia and Pacific } & Low data plan & USD 11.45 & USD 9.02 & USD 10.19 & USD 7.46 \\
\hline & High data plan & USD 1.69 & USD 1.31 & USD 1.57 & USD 1.14 \\
\hline & Overall & USD 6.57 & USD 5.16 & USD 5.88 & USD 4.30 \\
\hline \multirow{3}{*}{$\begin{array}{l}\text { North America } \\
\text { (excl. Mexico) }\end{array}$} & Low data plan & USD 5.84 & USD 4.45 & USD 5.77 & USD 4.36 \\
\hline & High data plan & USD 2.75 & USD 2.45 & USD 2.74 & USD 2.44 \\
\hline & Overall & USD 4.51 & USD 3.45 & USD 4.47 & USD 3.40 \\
\hline \multirow[t]{3}{*}{ Europe } & Low data plan & USD 4.52 & USD 4.02 & USD 3.90 & USD 3.80 \\
\hline & High data plan & USD 3.43 & USD 2.32 & USD 2.56 & USD 0.53 \\
\hline & Overall & USD 4.00 & USD 3.74 & USD 3.26 & USD 2.45 \\
\hline \multirow[t]{3}{*}{ South America } & Low data plan & USD 13.65 & USD 13.65 & USD 9.59 & USD 9.59 \\
\hline & High data plan & USD 7.07 & USD 5.28 & USD 4.29 & USD 3.29 \\
\hline & Overall & USD 9.89 & USD 8.87 & USD 6.56 & USD 5.99 \\
\hline
\end{tabular}

Note: Prices above reflect USD PPP and USD conversion rates according to OECD 2015 averages. ${ }^{6}$

The first observation is that as expected the price per GB decreases with volume and are lower at off peak times. One caveat on volume, however, is that this may not hold true in some OECD countries if the volumes considered here were greater than 50 GB per month. In Australia, for example, the NBN satellite pricing is less expensive per GB for mid-range tiers than higher tiers to manage available spectrum. By region the lowest average price for the high data plan was USD 1.69 PPP per 1 GB (USD 1.31 PPP when off-peak data is included) in the Asia Pacific region, followed by North America (USD 2.75 PPP) and Europe (USD 3.43 PPP). This order was reversed for the low data plan with the average price in Europe at USD 4.52 PPP, North America at USD 5.84 PPP and Asia Pacific at USD 11.45 PPP.

The average price of all of the low and high data plans in the sample across the four geographic categories suggest that Europe and North America have the lowest regional average prices when looking at the most basic plans offered, followed by Asia and the Pacific and South America. A number of interpretations may explain these results. In some regions, a primary factor may be that it is easier to offer satellite service if there is a higher population density. Even if there are "remote" areas, these areas are typically not as inaccessible as in other countries (such as the Amazon in Brazil). Secondly, the lower prices could reflect a competitive market, as there may be multiple satellite providers in a market who force the market equilibrium price down. However, the lower prices may also reflect economies of scale in other providers such as Europasat who are able to offer satellite broadband across multiple countries in Europe, due to the proximity and larger market to support a lower cost-high volume strategy. A further factor, not accounted for here, is the generation of satellite technology and hence the capacity available to operators that need to spread fair usage across users served. Finally, this report does not account for public funding that varies across all countries due to commitments to the satellite industry or policies related to universal service. In other words, some subsidies may be given directly to providers as opposed to users and these are reflected in prices. 
In Asia and Pacific, a higher cost of providing broadband satellite in some countries may be due to the higher availability of better Internet options for most customers. For instance, even Japanese islands are largely connected by fibre optic cables, making satellite an option only for the few very small and very remote islands that have yet to be connected by a faster means of broadband. This is also the case for Korea, a leader in broadband penetration among OECD countries for both fixed and mobile broadband (OECD, 2016b).

In South America, higher prices may be due to the emerging market conditions as well as the need to cover areas that are hard to reach. Meanwhile, in North America, it is notable that the United States is one of the few countries where companies offer bundled services with satellite television, perhaps representative of the popularity of the service in the country. Canada and the United States appeared to have more similar market characteristics than Mexico, where packages were more expensive than the other two countries.

Finally, the third difference is the disparity across regions in the ease of obtaining information regarding residential satellite broadband offers. Information on available prices and packages are readily available for Australia, Europe and North America, but less available in some other regions. This may reflect a larger and more established market in the regions where the satellite offers were easily accessible, even if the technology only represents a relatively small percentage of total broadband access. At the same time, as data for this report were gathered by consulting advertised offers on the World Wide Web, it may be the case that potential customers cannot easily access the Internet in many areas such as South America, or there are fewer potential customers able to pay the fees for broadband via satellite, and therefore maintaining an online sales portal is ineffective. Finally, the difficulty in finding information could be due to a low presence of the technology in the country due to a lack of demand, as perhaps is the case in the Asia Pacific region.

\section{Consumer Applications over Satellite}

When considering the actual usage conditions of broadband across any technology speed is a clear indicator, with download and upload speeds serving as the primary network performance characteristic advertised by Internet service providers. In the 2016 Measuring Broadband America Report, the Federal Communications Commission (FCC) included performance measurements from United States satellite broadband providers (2016a). The report calculated and compared median download and upload speeds among Internet service providers. While it found a decrease from 2015 when comparing the actual download speeds to advertised speeds for satellite Internet service providers, the report suggests that this may have been due to an increased number of customers on the network or increased usage of existing customers, which may be reversed with expected future launches to expand each network's respective capacity. Upload speeds remained fairly consistent. To the extent that satellite broadband providers are increasingly able to achieve download/upload speeds of 25/3 Mbps or higher, the services meet or exceed the current speed benchmark for broadband in the United States.

The average latencies of Hughes and ViaSat were 599 and 629 milliseconds (ms) respectively, in the 2016 FCC report (FCC, 2016a). However it should be mentioned that satellite providers have developed codec and modulation techniques to compensate for delays. The measurements reported here suggest that the transmission delay or the latency of the network connection is higher than terrestrial networks. This is due to the distances involved in satellite communications, especially with satellites in GEO or high altitude orbits, and it might be expected that there has been to date less use of real-time applications such as online multiplayer games, VoIP calls and video chat due to the higher average latency of transmission. Therefore, the primary implications for satellite broadband services are whether the typical speeds and other characteristics of the service allow for a good user experience, and whether data allowances accommodate preferred usage patterns. 
The video streaming use case can accommodate higher-latency relatively well, especially once the stream commences for a given video as these packet streams are buffered, meaning that a number of seconds or minutes of the content are pre-emptively downloaded and stored before the program begins to be displayed to the viewer. For example, Netflix requires only a 0.5 Mbps connection, but recommends at least 1.5 Mbps or higher to have a high video quality (Netflix, 2016). Latency is more of an issue when it comes to real-time interactive applications, as well as for cloud-based software that require a good deal of signalling between the client and server as well as virtual private networks.

That being said, several satellite providers are beginning to advertise the ability of the technology to support these applications, especially with the advent of the newer technologies include HTS systems which offer faster speeds and increased capacity. Xplornet, for example, advertises the use of Skype, Netflix, and YouTube on their plans with download speeds at or above $10 \mathrm{Mbps}$, suggesting that the company is confident that their newer satellites are able to offer speeds fast enough to support these applications (Xplornet Communications, 2016b). There are also some low-cost services which make it easier to stream on satellite connections. One such example is NightShift, which downloads content from Netflix during off-peak times, when data is often free of charge, and acts as a local DVR for consumers to watch downloaded content on demand (NightShift, 2017). With the next generation of satellite systems, there have been marked improvements in system capacity and latency using new technologies which make the technology more able to support the applications in demand by users. These new approaches and technologies will be discussed more in detail in the next section.

\section{Key Trends in Broadband Satellite Systems}

This section of the report describes some of the key trends and developments in the deployment of broadband satellite systems. These key trends and developments address the areas of improvement noted above that will enable future satellite systems to remain a viable access network alternative for broadband services. They are: $i$ ) the development of new low and medium earth orbit (LEO and MEO) satellite systems, ii) the design of new satellite launch technologies, and iii) the characteristics of next generation HTS GEO systems.

To date, broadband services have been provided primarily using geosynchronous (GSO) satellites. These satellites revolve around the Earth once in 24 hours, maintaining synchronization with the Earth's rotation, and are located in what is known as geostationary earth orbit (GEO). GEO satellites are typically large in size, expensive to build and launch, and have a large coverage area. Such satellites have the ability to provide service to large contiguous areas; an individual GEO satellite may provide service in a number of different countries at any given time, which can create significant scale effects.

In recent years, non-geosynchronous broadband proposals have become more common with the emergence of LEO and MEO constellations. Due to their lower altitudes and closer proximity to the earth's surface, most proposed LEO and MEO satellite systems will orbit the earth in less than 24 hours, hence earning the non-geosynchronous name as they appear to move relative to a fixed terrestrial point (JSAT International, 2016). The closer the satellite is to the earth, the faster it will move in its orbit and therefore the more satellites that will be required for a continued service to a fixed point. As LEO and MEO satellites are in a lower orbit than GEO satellites, more satellites typically are required in order to complete a global network than in GEO systems. Satellite lifetimes may also be shorter than their GEO counterparts, allowing for lower build and launch costs for an individual satellite, depending on the size and complexity of the satellite. 


\section{Introduction to Low (LEO) and Medium Earth Orbit (MEO) Satellite Systems}

The height of orbit for the satellite above the earth's surface has significant implications for system cost and the types of services delivered. A number of new LEO and MEO systems have been proposed or deployed to provide satellite broadband services in a much different fashion than traditional GEO satellites. Lower earth orbits significantly reduce the transmission power required and latency for satellite communications to GEO satellites. The resulting power savings and latency reductions can significantly decrease satellite equipment costs on the user premise, and allow for much higher quality of experience associated with real-time services such as multi-player services, VoIP calls and video chat. Indeed, LEO, MEO and GEO systems each have their own key characteristics as well as advantages and disadvantages (Table 3).

Table 3. Comparison of LEO and MEO Satellite System Characteristics

\begin{tabular}{|c|c|c|c|c|}
\hline \multirow{3}{*}{$\begin{array}{l} \\
\text { Transmission } \\
\text { Latency }\end{array}$} & \multicolumn{2}{|c|}{ MEO Satellite Systems } & \multicolumn{2}{|c|}{ LEO Satellite Systems } \\
\hline & Advantages & Disadvantages & Advantages & Disadvantages \\
\hline & $\begin{array}{l}\text { Significantly lower power } \\
\text { loss and transmission } \\
\text { delay than GEO }\end{array}$ & $\begin{array}{l}\text { More satellites than a } \\
\text { GEO system required to } \\
\text { create a global network }\end{array}$ & $\begin{array}{l}\text { Can carry real-time } \\
\text { services (latency 20-40 } \\
\text { times less than GEO) }\end{array}$ & $\begin{array}{l}\text { More complex satellite } \\
\text { system which increases } \\
\text { costs }\end{array}$ \\
\hline Coverage (GEO) & $\begin{array}{l}\text { Global coverage using } \\
\text { as few as } 10 \text { satellites }\end{array}$ & $\begin{array}{l}\text { Full system deployment } \\
\text { to operate } \\
\text { network }\end{array}$ & $\begin{array}{l}1600 \text { times less } \\
\text { transmission path loss } \\
\text { than GEO because orbit } \\
\text { up to } 40 \text { times closer } \\
\text { earth surface }\end{array}$ & $\begin{array}{l}\text { Need for large number of } \\
\text { satellites to complete } \\
\text { global constellation } \\
\text { network (i.e., } 50 \text { satellites } \\
\text { or more) }\end{array}$ \\
\hline Services & $\begin{array}{l}\text { A compromise solution } \\
\text { that provides good } \\
\text { trade-off between total } \\
\text { number of satellites, } \\
\text { coverage, and types of } \\
\text { services supported }\end{array}$ & $\begin{array}{l}\text { Few systems have been } \\
\text { deployed, and thus } \\
\text { limited experience with } \\
\text { system operations }\end{array}$ & $\begin{array}{l}\text { Well suited for mobile } \\
\text { services due to low } \\
\text { latency, small light- } \\
\text { weight and low-cost } \\
\text { handsets }\end{array}$ & $\begin{array}{l}\text { Due to stronger } \\
\text { gravitational field, satellite } \\
\text { lifetime typically } 7 \text { years } \\
\text { versus } 12-18 \text { years for } \\
\text { GEO }\end{array}$ \\
\hline
\end{tabular}

Source: Joseph N. Pelton, "Satellite Orbits for Communications Satellites" (pp. 100-102), Handbook of Satellite Applications, Volume 1, Springer Reference, 2013.

\section{Proposed Broadband LEO Systems}

Numerous LEO satellite systems for land, mobile, earth observation and remote sensing applications have already been deployed, not to mention the International Space Station which also operates in LEO. In addition to these existing operators, a number of new LEO systems are currently planned with the goal of providing satellite broadband using non-geostationary orbit satellite constellations, operating in LEO, and providing low latency transmission capable of supporting most real-time services commonly carried in broadband service.

Several of the companies planning these multi-satellite constellations have said they will deliver Internet access to customers in remote and underserved regions. Some systems may have the capability to provide coverage even in high latitude polar regions, currently beyond the reach of GEO satellites and where terrestrial technologies may be uneconomical, such as Alaska, northern Canada, Russia, and the far north of the Nordic region. Reflecting the significant interest and innovation occurring in this space, the systems described below represent a non-exhaustive list of recently proposed systems.

\section{OneWeb}

WorldVu Satellites Limited, doing business as OneWeb, is planning to launch and operate a nongeostationary constellation of approximately 720 satellites in LEO, near an altitude of $1200 \mathrm{~km}$ (WorldVu Satellites Limited, 2016; FCC, 2016a). OneWeb states that their satellites will make broadband accessible to many individuals who have limited to no service today, including people in rural and remote areas in 
both developed and developing countries. The network aims to support applications such as community and residential Internet connectivity, cellular backhaul, mobility services for vehicle, aeronautical, and maritime use, and emergency communications. Communications with the satellite system will take place in the $\mathrm{Ku}$ - and $\mathrm{Ka}$ - frequency bands.

In addition, OneWeb has proposed another non-geostationary satellite constellation using V-band frequencies, as a complement to its Ku- and Ka-band LEO broadband operations (WorldVu Satellites Limited, 2017). This second constellation would consist of an additional V-band payload on the OneWeb satellites operating in LEO, as well as adding approximately 1280 satellites operating in MEO.

\section{Boeing}

The Boeing Company plans to launch and operate a non-geostationary constellation operating in LEO that aims to offer global satellite broadband service. The constellation would consist of 2956 satellites in total. Boeing's initial deployment would be 1396 satellites operating in LEO near an altitude of $1030 \mathrm{~km}$ and 1082 km using V-band frequencies (The Boeing Company, 2016a; FCC, 2016c). Boeing states that its constellation will introduce new satellite-delivered broadband services, enhancing competition and the availability of broadband access in the United States and globally in addition to competing effectively with terrestrial wireless and wireline services. The constellation would also provide high data rate connectivity with low latency to support a wide range of Internet and communication services for residential, commercial, institutional, governmental, and professional users worldwide.

It has also proposed a second V-band non-geostationary hybrid system consisting of 132 satellites operating in LEO at an altitude of $1056 \mathrm{~km}$ and 15 satellites operating in highly-inclined orbits in MEO with an altitude between approximately 27355 km and 44221 km (The Boeing Company, 2017).

\section{LeoSat Enterprises}

LeoSat plans a non-geostationary constellation of between 78 and 108 small high-throughput Ka-band satellites operating in LEO (LeoSat, 2016a; LeoSat, 2016b). LeoSat states that its constellation will offer secure high-speed broadband with low latency to provide global connectivity for large corporations and government agencies. In particular, the constellation's proposed low altitude of $1400 \mathrm{~km}$ along with its optical inter-satellite links will be the key to maintaining its low latency. LeoSat intends to focus on customers seeking higher capacity, short time delay and higher security. The proposed satellites will be in six orbital planes, connected by optical inter-satellite links, and would deliver Ka-band broadband. LeoSat plans to work with European satellite manufacturer Thales Alenia Space to manufacture the satellites, begin launching satellites in 2019, and offer service from 2020 (Leosat, 2016c).

\section{Telesat}

Telesat is planning a non-geostationary high throughput satellite system in LEO. It intends to develop a constellation of at least 117 satellites, providing global broadband coverage, including in unserved and underserved areas (Telesat, 2016a). Telesat states that the service provided will have significantly lower latency than GEO, equivalent to or even lower than terrestrial networks in some cases. The satellites will be located in two sets of orbits, a polar orbit at an altitude of $1000 \mathrm{~km}$ and inclined orbits at an altitude of $1248 \mathrm{~km}$; the satellites in both orbits will be connected via optical inter-satellite links. It has procured two Ka-band satellite prototypes which it plans to launch in 2017 as part of a test and validation phase for its constellation in development (Telesat, 2016b). Telesat has contracted with Space Systems Loral (SSL) and Surrey Satellite Technology Limited (SSTL), an independent British company within the Airbus Defence and Space group, for the procurement of the prototypes. Telesat has also proposed similar operations in the V-band (Telesat, 2017). 


\section{SpaceX}

SpaceX plans a LEO satellite constellation to provide broadband service, using a total of 4,425 satellites operating in 83 orbital planes ranging from $1110 \mathrm{~km}$ to $1325 \mathrm{~km}$. The planned system would operate in the Ku-band for end-user links and the Ka-band for gateway communications. The constellation would provide broadband and communications services for residential, commercial, institutional, governmental, and professional users worldwide (SpaceX, 2016). SpaceX is additionally planning to augment operations for this LEO constellation using the V-band, and has made regulatory filings for an additional very low Earth orbit satellite constellation made up of 7518 satellites operating at altitudes from $335 \mathrm{~km}$ to $346 \mathrm{~km}$, with the goal of added capacity and spectral diversity. SpaceX plans to deliver high speed, high bandwidth, low latency broadband services that are competitive with terrestrial alternatives (SpaceX, 2017).

\section{Other LEO Systems}

There have also been other proposals and additional filings with the ITU for other LEO satellite constellations operating in different parts of the VHF-, UHF-, X-, Ku-, and Ka-band spectrum (FAA, 2015).

\section{Broadband MEO Systems and other NGSO Systems}

O3b Networks has launched a 12 satellite global constellation in an $8062 \mathrm{~km}$ MEO orbit in 2014 to deliver high-speed broadband links over the Ka band (O3b, 2016). With each satellite supporting 10 steerable spot beams of $700 \mathrm{~km}$ in diameter, the constellation coverage for service stretches between the 45-degree north and south latitudes. Each spot beam delivers up to 2 Gbps (1 Gbps in each direction). The O3b Network satellite system does not provide DTH satellite service. Instead, O3b Networks provides "middle mile" transport to connect MNOs, terrestrial ISPs, large commercial users or government agencies to the Internet. For example, O3b uses its MEO satellite system to deliver Internet access to a remote region in Brazil (Box 3).

\section{Box 3. Use of O3b Networks MEO system to provide middle mile connectivity to remote area in Brazil}

O3b worked with its local Amazonas partner Ozonio to bring high performance broadband to the middle of the Amazon in Tefé, Brazil. Tefé is a very remote town of 65000 people; there are no roads into Tefé, it is accessible only by plane or a 3-day boat ride from Manaus. Just as there are no roads, there are also no fibre-optic telephone lines because it is too remote and costly to lay the fibre through the jungle. Voice and data communications are delivered over satellite and microwave, meaning that Tefé had only older generation $2 \mathrm{G}$ mobile data services with limited capacity. As a consequence, they could not support modern applications like WhatsApp, Facebook, Skype video, business systems with cloud-based applications or delay-sensitive e-commerce. Even web browsing tended to be very slow.

O3b and Ozonio built a node site to connect to the O3b constellation, and then added three microwave links and Wi-Fi to spread the capability over the entire town of Tefé as well as to all the towns within the beam, thus connecting over half a million people to 4G. The broadband service was demonstrated in June 2016 and by July 2016 many local businesses and consumers were using Facebook, streaming videos, booking travel reservations, and accessing media-rich websites. In addition, university students were able to access research and online courses and the hospital could send medical image files and conduct video consults with doctors in major cities. It is expected that this satellite service will be an enabler of economic growth and social engagement for Tefé that could not be delivered by the previous options available to the town.

Additionally, there have been several other NGSO systems proposed. As an example, Boeing has proposed a NGSO system, which would operate in the Ka- band and consist of 60 satellites operating in highly inclined orbits at higher altitudes (between approximately 27000 and $44000 \mathrm{~km}$ ) to provide 
broadband services (The Boeing Company, 2016b). There have also been additional MEO and highlyelliptical orbit (HEO) ${ }^{7}$ systems planned. ViaSat has planned a MEO system consisting of 24 satellites in separate inclined circular orbital planes at an altitude of $8200 \mathrm{~km}$, operating in the Ka- and V-bands, and providing broadband services, including to those who have been "left behind" by terrestrial broadband providers (ViaSat, 2016). Other companies have proposed HEO satellite systems, including Space Norway, to provide broadband connectivity to the Arctic region, and Karousel, to provide video content. ${ }^{8}$

\section{New Launch Technologies}

The growing interest in LEO and MEO satellite systems corresponds with increasing innovation in satellite launch systems. The potential benefit of lower launch costs will favour the viability of these LEO and MEO systems, as well as GSO satellites. This section of the report discusses new developments in launch technologies that could change the economic equation of satellite systems.

Although launch activity in the space transportation industry has been relatively constant over the past five years or so, there are now about 70 existing or new launch vehicles, and reusable rockets have been successfully launched and recovered (Masunaga, 2016). The industry continues to evolve in both its technology and commercial offerings. Additionally, several new launch vehicles are being developed to deliver small satellites into orbit. A 2015 projection predicts a worldwide average of 17 commercial GSO launches for 2015 through 2017 and an average of 13.1 commercial NGSO launches per year during the period from 2015 through 2024 (FAA, 2015: 5, 21). Data are available on civil, military and commercial orbital launches by country in 2015 (Table 4).

Table 4. Breakdown of Satellite Launches in 2015

\begin{tabular}{|l|c|c|c|c|}
\hline \multicolumn{1}{|c|}{ Country/Region } & Civil & Military & Commercial & \multicolumn{1}{c|}{ Total } \\
\hline Russian Federation & 14 & 7 & 5 & 26 \\
\hline United States & 4 & 8 & 8 & 20 \\
\hline $\begin{array}{l}\text { People's Republic of } \\
\text { China }\end{array}$ & 12 & 7 & 0 & 19 \\
\hline European Union & 5 & 0 & 6 & 11 \\
\hline India & 3 & 0 & 2 & 5 \\
\hline Japan & 1 & 2 & 1 & 4 \\
\hline Iran & 1 & 0 & 0 & 1 \\
\hline TOTAL & $\mathbf{4 0}$ & $\mathbf{2 4}$ & $\mathbf{2 2}$ & $\mathbf{8 6}$ \\
\hline
\end{tabular}

Source: FAA (2016)

Reusable rocket technology has the promise of changing he cost calculation for both traditional and smaller satellite launches. One example of reusable rocket hardware is Blue Origin's New Shepard system, which the company plans to offer commercially for space tourism and research applications (Foust, 2016a; Foust, 2017). SpaceX's Falcon 9 is another example of a reusable rocket that is designed to launch satellites and space station supply missions (Foust, 2016b; Henry, 2017). While the commercial impact of such reusable rockets is still in its early stages, they have the potential to lower launch costs significantly. A typical SpaceX launch costs USD 62 million, and SpaceX has indicated that it intends to apply price reductions for those customers launched using a flight-proven first stage launch vehicle (de Selding, 2016a).

Some reduction in launch and deployment costs may also result from the decreasing mass of the individual satellites, including GSO satellites. Satellite designs using new electric propulsion systems rather than chemical propulsion for orbit-raising offer the prospective of reducing the mass of the propellant (FAA, 2016: 8). However, using electric propulsion does increase the time required for orbit- 
raising. In addition, keeping satellite mass low may enable two GSO satellites to be launched together on the same vehicle, called dual-manifesting (Boeing, 2014).

A number of space companies are developing new launch vehicles aimed at deploying means to launch small satellites, which may in some cases include those that would operate in LEO and provide broadband service. To date, small satellites, such as CubeSats, ${ }^{9}$ have typically been launched as secondary payloads alongside the primary payload, and have taken advantage of launch opportunities as they arise. This can constrain a small satellite operator's choice of deployment orbits and launch schedules, as it must wait for a launch opportunity that can accommodate a secondary payload. This in turn makes deployment more difficult for these satellites lacking the ability to manoeuvre themselves into a particular mission orbit. A number of companies have indicated that they are developing lower-cost small satellite launch vehicles (Foust, 2016c, 2014; Warwick, 2015), such as the Virgin Galactic's LauncherOne (now Virgin Orbit) (Virgin Galactic, 2017), Rocket Lab's Electron (Rocket Lab, 2017), and Vector Space System's Vector-R and Vector-H (Vector, 2017), among others.

Notwithstanding decreasing launch costs, commercial satellite operators face certain risks associated with space operations, such as launch delays or failures, on-orbit deployment failures or solar storms affecting on-orbit performance. Many satellite operators mitigate these risks using various insurance instruments that have emerged to accommodate commercial space sector operations (OECD, 2014). In 2014 there were 70-80 launches on average of which 30-40 were insured. The insured launches carried 1530 LEO satellites, and 20-25 GSO satellites. For an LEO satellite, the average insured value in 2014 was approximately USD 40 million for a period of five years, while GEO satellites are insured up to USD 100 to USD 400 million for 15 years (OECD, 2014). Additionally, the insured life of the satellite addresses some of the hazards facing satellites in orbit, such as those created by orbital debris (Box 4). This demonstrates some of the market's attempts to mitigate risks, as well as the large ramifications should a satellite encounter a problem at launch or over the course of its mission.

\section{Box 4. Orbital Debris Mitigation}

In space, even small objects can produce significant impact damage due to the relatively high velocities involved. Additionally, debris is self-propagating, meaning that collisions between debris or between debris and non-debris objects create additional debris. ${ }^{10}$ Growth in the orbital debris population may increase the cost and complexity of space operations.

Consideration of orbital debris mitigation in spacecraft design and operation can play an important role in preserving access to space for the long term. Some factors in evaluating whether a particular satellite or constellation will operate in accordance with orbital debris mitigation best practices may include the ability of satellites to perform manoeuvers, the selection of orbits, the availability of tracking information, the total orbital lifetime of an individual satellite and reliability of any measures designed to shorten orbital lifetime. Generally, space traffic operations policies to encourage smart space operations, object and debris tracking and sharing of operational data will become increasingly important as the number of manmade objects in space increases.

The United Nations (UN) Office for Outer Space Affairs has developed a series of Space Debris Mitigation Guidelines, which were endorsed by the UN General Assembly in 2007 (UNGA, 2007). The UN recommends that member states and international organisations voluntarily take measures to ensure that the guidelines are implemented, to the greatest extent feasible, through space debris mitigation practices and procedures (UNOOSA, 2010). The UN guidelines were in turn based on guidelines developed by the Inter-Agency Space Debris Coordination Committee (IADC), an international governmental forum for the exchange information on space debris research activities between its member space agencies (IADC, 2016). The ISO standard 24113 followed in 2010 as the top-level standard in a group of standards all addressing mitigation tactics in space debris (OECD, 2014). The IADC is currently studying whether there may be revisions to its guidelines appropriate to address large NGSO constellation deployments. 


\section{Geostationary High-Throughput Satellite (HTS) Systems}

HTS systems are generally defined as geostationary satellite systems that use multiple spot beams to cover the service area rather than a small number of wide beams. The high-throughput satellite acts as an interface to carry user traffic back and forth between the users and the terrestrial network, through user end small satellites and gateway stations which connect the satellite to the terrestrial network (Lutz, 2016). Several HTS GEO systems have been launched and are in operation in the Ku- and Ka-bands to provide Internet services in the DTH and community aggregator models.

Similar to terrestrial cell tower networks, the throughput of the satellite system increases because spot beams allow higher power transmission that are more efficient and that permit a higher rate of data transfer. This also allows for less expensive end user terminals. The use of spot beams permits frequencies to be reused multiple times, thereby boosting overall system capacity through the increased bandwidth available (CRTC, 2014). For example, Australia is covered by a combination of narrow and wide spot beams to deliver high-speed Internet service (Figure 3).

Figure 3. Spot Beam Coverage of NBN High-Throughput Satellites

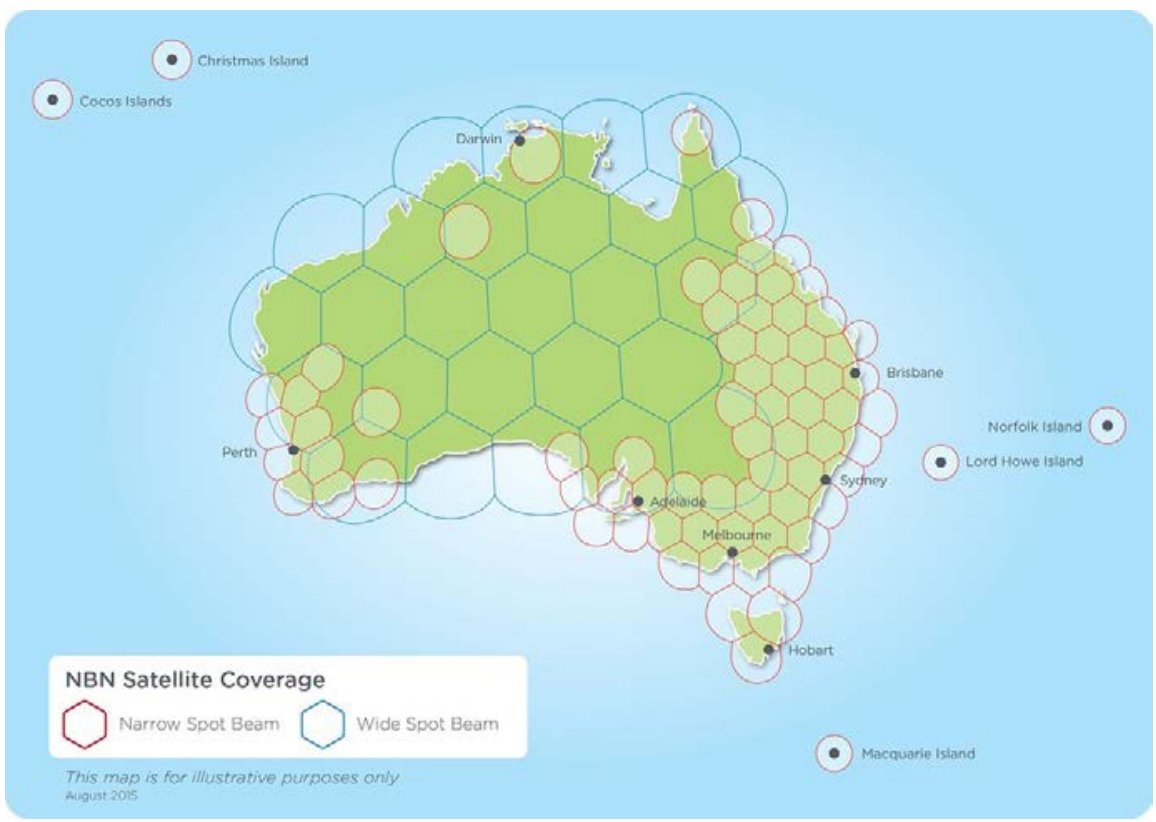

Source: NBN.Co, "Satellite FAQ: Everything You Need to Know About Sky Muster, http://www.nbnco.com.au/blog/the-nbnproject/five-questions-with-nbns-satellite-program-director.html.

The overarching trend in new HTS systems is the significant increase in available capacity. The first HTS, Thailand's IPSTAR, launched in 2005 with 45 Gbps of capacity (Musey, 2016). This was significant for its time with prior satellites limited to the 5-10 Gbps range. In 2011-2012, ViaSat-1 and EchoStarXVII launched with roughly 130 to 140 Gbps of capacity each.

Today, private and public sector deployments and plans for new higher-capacity HTS systems are underway in earnest. Seeking to incentivize the private sector, Argentina has authorised an HTS technology trial to be conducted by AT\&T's subsidiary, DIRECTV Argentina, in order to identify the most economically viable ways to expand coverage in the country (Box 5). The governments in Russia and Italy are both deploying HTS systems to support the broadband goals of each country (Box 6). Elsewhere, companies are announcing aggressive plans for HTS system deployments. In 2016, ViaSat Inc. announced 
that it was launching ViaSat-2, which will double it satellite capacity to 300 Gbps, increase its coverage area sevenfold and provide user speeds of 25-100 Mbps, with the goal of unlimited data packages. In addition, ViaSat unveiled its plan for a global system consisting of three 1 Tbps throughput Ka-band satellites with exponentially higher capacity and speeds (de Selding, 2016b).Hughes provides an additional example, with its successful launch of the EchoStar XIX satellite in December 2016 which features 138 spot beams supporting more than 220 Gbps throughput (Hughes, 2016a).

\section{Box 5. Trial of Private Commercial HTS Service in Argentina}

In August 2016, the Argentine government authorised the trial of a broadband satellite project to be conducted by AT\&T's subsidiary, DIRECTV Argentina, for a period of 2 years. This trial will provide helpful information about the performance and adoption residential satellite broadband service in both rural and suburban areas in order to find economically viable ways to expand broadband coverage in Argentina. The trial will use up to $216 \mathrm{MHz}$ in the Ka-band communications payload of the United States Spaceway2 satellite, located at 99.075 degrees west.

The main challenges with scaling residential satellite broadband are capacity and cost. This trial invests in HTS technology, which helps to exponentially multiply the satellite capacity, allowing a wider coverage and reducing operational costs vis-a-vis other satellite technologies.

Residential Satellite Internet Service in rural areas is growing rapidly worldwide since the introduction of HTS technology. In Argentina, the trial has been designed to initially cover 82 municipalities in the Buenos Aires province, with coverage over approximately $2 \mathrm{M}$ households, of which roughly $1.6 \mathrm{M}(79 \%)$ are in rural or suburban areas and, of those, approximately 386K (24\%) are rural households.

DIRECTV Argentina estimates that the broadband availability in the geography covered by the Spaceway2 satellite currently is only about $63 \%$, with service speeds of $1-3 \mathrm{Mbps}$, and a small coverage of speeds up to $5 \mathrm{Mbps}$. The Trial is currently offering speeds of up to $15 \mathrm{Mbps}$ throughout $100 \%$ of the geography. In addition to improving access quality, the trial will help grow broadband penetration in municipalities that other technologies have not yet been able to reach, and will incentivise competition in those where users have only one service option.

\section{Box 6. HTS GEO Systems in Practice}

The Russian Federation (from here on Russia), Italy and Canada have established different national satellite systems to meet their respective broadband goals given specific related circumstances in each country.

\section{The Russian Federation's Satellite System of High-Speed Access (SSHSA)}

Russia has launched two satellites to create the SSHSA in the Ka-band to deliver low cost broadband services such as e-mail, VoIP and digital television over IP networks (IPTV) throughout Russia to meet the goals of i) improving societal development and overcoming "digital inequality" within rural regions, ii) spurring technological development of national industries in the production of Ka-band equipment, and iii) continuing to use the reserved orbital-frequency resource of the Russian Federation in the Ka frequency band. The SSHSA system consists of Western "Dubna" and Eastern "Khabarovsk" service zones served by the Express-AM6 satellite (put in operation June 2016) and ExpressAM5 satellite (launched April 2015), respectively, with 7 Gbps of total capacity from 12 transponders in each. Equipment installed in "Dubna" and "Khabarovsk" service zones can provide connections to 100000 subscribers with the potential to serve 200000 subscribers. A typical subscriber land satellite communication station (SLSCS) includes a 0.7-0.9 m. diameter antenna, a $2 \mathrm{~W}$. transceiver and a satellite modem with an Ethernet output. The cost of a typical SLSCS starts at USD 562 (USD market rate of 62.23 RUB on 10 October, 2016), comparable to the cost of a midrange smartphone. Since the beginning of operation, more than 1500 subscribers have been registered in the SSHSA.

\section{Italy's URBIS Satellite System}

Italy has an EU commitment to provide its population with Internet access of more than $30 \mathrm{Mbps}$, and $85 \%$ of the population with more than $100 \mathrm{Mbps}$ by 2020. The Italian Space Agency (ASI) launched the URBIS project (UltRa Broadband Italian Satellite) in collaboration with Eutelsat and Telespazio to meet this EU goal. The design capacity of 
URBIS is 1 Tbps for $1-1.5$ Million households concentrated in a limited area (the Italian surface is about 300000 sq. $\mathrm{km}$ ). This high throughput concentration (about 100 times more bits $/ \mathrm{km}^{2}$ than HTS) can provide over 1 Mbps per user, and is referred to as UHTS (Ultra HTS) by the ASI. UHTS is dramatically different from standard HTS, which provides lower speeds per user over much larger footprints. The system will use Ka-band for satellite-user terminal links and Q/ $\mathrm{V}$ band for the satellite-feeder links to maximise spectrum available to the user terminal. The basic design criteria for the URBIS system are:

- Reduced beam spacing $\left(<3^{\circ}\right)$, providing considerably higher capacity density in terms of $\mathrm{Kbps} / \mathrm{m}^{2}$

- Two satellites, assuring the coverage of the Italian service area from two different orbital positions, in-orbit redundancy and system robustness

- 40 to 80 spot beams per satellite, 2 beams covering each point in the coverage, and $12+$ on ground gateways and switchless gateway redundancy

Each URBIS satellite beam dedicates 400 Mbps to video content delivered in IP multicast format for a total of 800 Mbps of video content covering any spot beam area. URBIS system architecture provides for content distribution network (CDN) functionality allowing end user terminals, at backhaul or at home, to locally store content with the most demand, using capacity available during non-peak hours to refresh local storage units. Using this live multicast solution each user terminal would have access to $400 \mathrm{Mbps}$ multicast live video content (corresponding to the most popular 100 to 400 TV channels in each spot) from each satellite, which would allow different TV channels to be received simultaneously for viewing by various members of the same household.

URBIS offers connectivity via satellite directly to the end user as well as providing backhaul for local networks (typically wireless). Though it is often viewed as a last resource due to its limited bandwidth per user compared to other options, this case in Italy demonstrates that through a specific design and extensive re-use of complete Ka- and Q/V bands, it is possible to offer fibre-like performances via satellite at costs lower than fibre in sparsely populated areas.

\section{Canada's High-Throughput Satellites}

Since 2012, Xplornet has used two HTS, ViaSat-1 and EchoStar XVII, to offer up to 10/1 Mbps but only has coverage near the Canada-US border (CRTC, 2014:37). Going forward, Xplornet has also purchased all of the Canadian capacity on two new HTS (EchoStar XIX and ViaSat-2) to offer speeds up to 25/3 Mbps. EchoStar XIX also covers more of Canada than EchoStar XVII, allowing for wider service coverage. Canadian satellite operator Telesat is also expected to expand HTS coverage in Canada through the launch of its Telstar 19 Vantage satellite in 2018. It will include significant coverage in Canada's northern regions. The growth of HTS is an important trend for areas that are challenging to serve via terrestrial technologies.

The growth of HTS GEO systems combined with other developments has led to steadily decreasing costs per bit for satellite capacity. It has also allowed for a greater amount of dynamism for an industry segment that has traditionally had more stable revenues and technological cycles. However, with this comes the potential for greater uncertainty about the long-term revenue prospects for a given satellite platform or market segment. One question operators can face is whether demand growth will outpace the rate of declining unit prices such that it supports growing revenues overall. ${ }^{11}$ To help mitigate the risks of being undercut, some operators are exploring the potential for satellites with shorter useful lives though whether this is economically practical is unclear (de Selding, 2016c). Some countries that have extensively deployed fibre backbone networks across their territory, have expressed a preference for terrestrial solutions over satellite broadband solutions due to the shorter working lifetimes of satellites that require more continuing planning efforts as compared to terrestrial systems, though there are continuing costs associated with terrestrial systems as well.

\section{Changing Economics of Broadband Satellite}

This section examines how the economics of broadband satellite services are changing given the rapid introduction of technological innovations discussed in Section 2. As new technologies are incorporated, such as new HTS systems, what will be the changing role of using satellites to deliver broadband services, including in rural and remote areas, within the larger overall broadband ecosystem? This section addresses that question by first identifying the competitive network options to provide middle mile and direct-to- 
home broadband services. Then, it discusses what is required for satellites to be a competitive solution in these markets.

\section{Set of Competitive Options to Offer Broadband Service}

This discussion of broadband options is broken into two categories: the middle mile and last mile network segments. The "last mile" or local access network is the portion of the network that connects directly to the end user from the closest aggregation or switching point of the network (which may be a spacecraft). The "middle mile" network represents the segment of the broadband network that connects the local access network to the core or global Internet network. Neither network segment is restricted to a mile in length, instead serving as representative terms to identify the final and middle portions of the broadband service distribution network.

\section{The Last Mile - Residential Broadband Network Options}

A detailed breakdown and analysis of the economics of all the last mile network options available to deliver broadband services to residential consumers is beyond the scope of this report. It is possible for an individual country to undertake such an exercise, as Sweden is currently doing by mapping all business, residential and highway network deployment costs, though this is a major undertaking. Instead, a straightforward taxonomy of last mile solutions is provided, including the representative upfront fixed costs of these various solutions, as they are publically available or currently known to provide broadband service in remote rural areas at very low rates of penetration over the next three years. While upfront fixed costs represent a significant determining factor in identifying the best broadband option for a particular area, operating costs can also be an important consideration, though they were not included in this analysis, due both to their magnitude and to the extent they might vary considerably across broadband options. For example, limitations in the working lifetimes of satellites may require more continuous planning, although there are continuing costs associated with terrestrial systems, including life cycles, as well. Thus, this taxonomy is useful for comparative purposes of understanding the relative fixed costs of broadband options, but including the operating costs of each option is outside the scope of this analysis. These would need to be included to complete the economic picture required for the purposes of full and comprehensive decision making. Generally speaking, the last mile solutions are categorised into four categories including terrestrial wireline, terrestrial wireless, stratospheric technologies (e.g., balloon and drones), and satellite solutions.

While costs will differ substantially across different countries depending upon local factors, some indicative figures can be estimated to compare the potential amounts required across different technologies for new deployments. Local factors like distance and topography will affect the potential infrastructure costs, or citizens may even help to lay fibre themselves, as farmers in New Zealand have done on their properties to reduce costs. The terrestrial wireline solutions available in rural locations include Fibre-tothe-Home (FTTH), cable Hybrid Fibre Coax (HFC), and Digital Subscriber Line (DSL). FTTH networks can in some locations deliver up to 1 Gbps broadband service and may cost USD 17200 per user (USD 17 per Mbps) ${ }^{12}$ in rural areas assuming a $10 \%$ penetration of households (Calix, 2010). ${ }^{13}$ Cable HFC networks today can cost USD 4400 per user (USD 175 per Mbps) under similar conditions to offer 25 Mbps broadband services (Reed, 2016). ${ }^{14}$ With detailed DSL costs not publically available, this analysis assumes rural DSL can provide 2 Mbps broadband service at USD 3000 per user (USD 1500 per Mbps). For all these figures, it should be borne in mind that deployment cost will vary according to geography, legacy technology used in different countries, as well as differences in regulatory regimes.

The wireless terrestrial options include Wi-Fi, LTE, WiMax and television white spaces (TVWS) technologies. The stratospheric solutions reflect new innovations in the use of balloons (e.g., Project Loon by Google) or drones (e.g., Aquila project by Facebook) to support delivery of local broadband service. 
These approaches are in the trial stage for technical scale and operational feasibility. ${ }^{15}$ Recent academic research estimates the upfront capital expense to deliver 2 Mbps broadband service to roughly $10 \%$ of homes in remote towns in the Andes region of Peru to be USD 4215 per user using Wi-Fi (USD 2105 per Mbps), USD 3035 per user using WiMax (USD 1515 per Mbps), USD 2950 per user using LTE (USD 1 475 per Mbps), USD 2570 per user using TVWS (USD 1285 per Mbps), and USD 1540 per user using a stratospheric solution (USD 770 per Mbps) (Espinoza, 2016). This same research estimates the capital expense of these stratospheric solutions using balloons using LTE to end users and WiMax as the backhaul.

Finally, the capital expenditures for a $10 \mathrm{Mbps}$ broadband satellite service using GEO satellites were estimated to be USD 1400 per subscriber in 2010 (USD 140 per Mbps), (FCC, 2010) and have likely decreased since then. Estimating the cost of proposed LEO systems is more difficult, and requires analysis of total system cost (including cost per satellite and per user terminal) alongside the estimated number of users. One example of a proposed constellation, OneWeb, calls for 900 satellites, each at a cost of USD 500000 or less, with a projected system cost of USD 3.5 billion (de Selding, 2016d). OneWeb also estimates that the cost of satellite terminals will be USD 250 (Boyle, 2015). Simplistically assuming the OneWeb LEO system achieves 1 million users after three years yields an estimated cost per user of USD 3750 (or USD 375 per Mbps assuming a 10 Mbps service).

Given the estimates for the cost of broadband network options described above, there are different ways to illustrate the cost per user and cost per Mbps, respectively, versus broadband service speed (Figure 4 and 5). These metrics show that cost per user increases with speed (Figure 5), while the cost per Mbps decreases with speed (Figure 5). ${ }^{16}$ The underlying assumption behind these graphs is that the network costs reflect deployment of the network technology in a rural setting where the broadband service penetration is only $10 \%$. The graphs predict parity in the cost per user for terrestrial wireless networks and GEO satellite broadband at this penetration level. Increasing penetration rates above $10 \%$, however, results in significant cost savings for terrestrial wireless systems relative to GEO satellite as, for example, the cost at 30\% penetration for a $12 \mathrm{Mbps}$ broadband service using Wi-Fi falls to USD 1060 per user (USD 90 per Mbps). This is true due to the higher proportion of fixed costs per user in terrestrial wireless systems compared to satellite. FTTH networks deliver the lowest cost per Mbps as expected, though the overall cost per user for delivering 1 Gbps using FTTH is very high. Again, as the penetration rate increases on the terrestrial wireless systems above 10\%, the cost per Mbps will fall below USD 100 per user, making this solution a viable and cost effective broadband solution.

These comparisons in the cost of speed and deployment are key metrics to compare the different fixed broadband distribution. In areas where the density of users supports higher fixed costs of deployment, terrestrial wireline technologies may hold the advantage in cost per user. In rural circumstances with low initial rates of subscription, however, these solutions are at a significantly higher cost and not likely to be deployed. In contrast, terrestrial wireless technologies such as Wi-Fi, LTE, WiMax and TVWS, are more economically attractive to deliver relatively slower broadband speed below 10 Mbps over the last mile connection to end users. Even though they have a higher cost per Mbps as compared to wireline options, the lower fixed costs of deployment provide a much lower cost per user or total cost of deployment.

The trial-stage stratospheric solutions are the lowest fixed cost solutions available because of the high degree of shared costs (the coverage area for a balloon is $70 \mathrm{Km}$ in diameter) compared to any terrestrial solution, and the avoidance of expensive launch fees. This high degree of sharing, however, limits the ability to support higher broadband service speeds, particularly if spectrum allocations consistent with LTE or WiMax bands are used (e.g., $20 \mathrm{MHz}$ in the uplink and downlink). Finally, it is important to note that these indications are for new deployments and thus costs will vary depending on inherited networks and local circumstances such as distance from existing facilities such as middle mile networks. In particular, the cost per household for terrestrial technologies tends to increase steadily as deployment becomes more difficult due to lower population density or more difficult terrain and one approaches the $100^{\text {th }}$ percentile of 
coverage (FCC, 2010). Satellite costs tend to be flat on a per household basis, which can make satellite relatively more attractive for lower density areas and remote locales. Policymakers may find it useful to examine where these relative cost curves intersect in evaluating particular local circumstances.

Figure 4. Comparison of Cost per User versus Speed for Rural Broadband Systems at Low Rates of Adoption (less than 10\%)

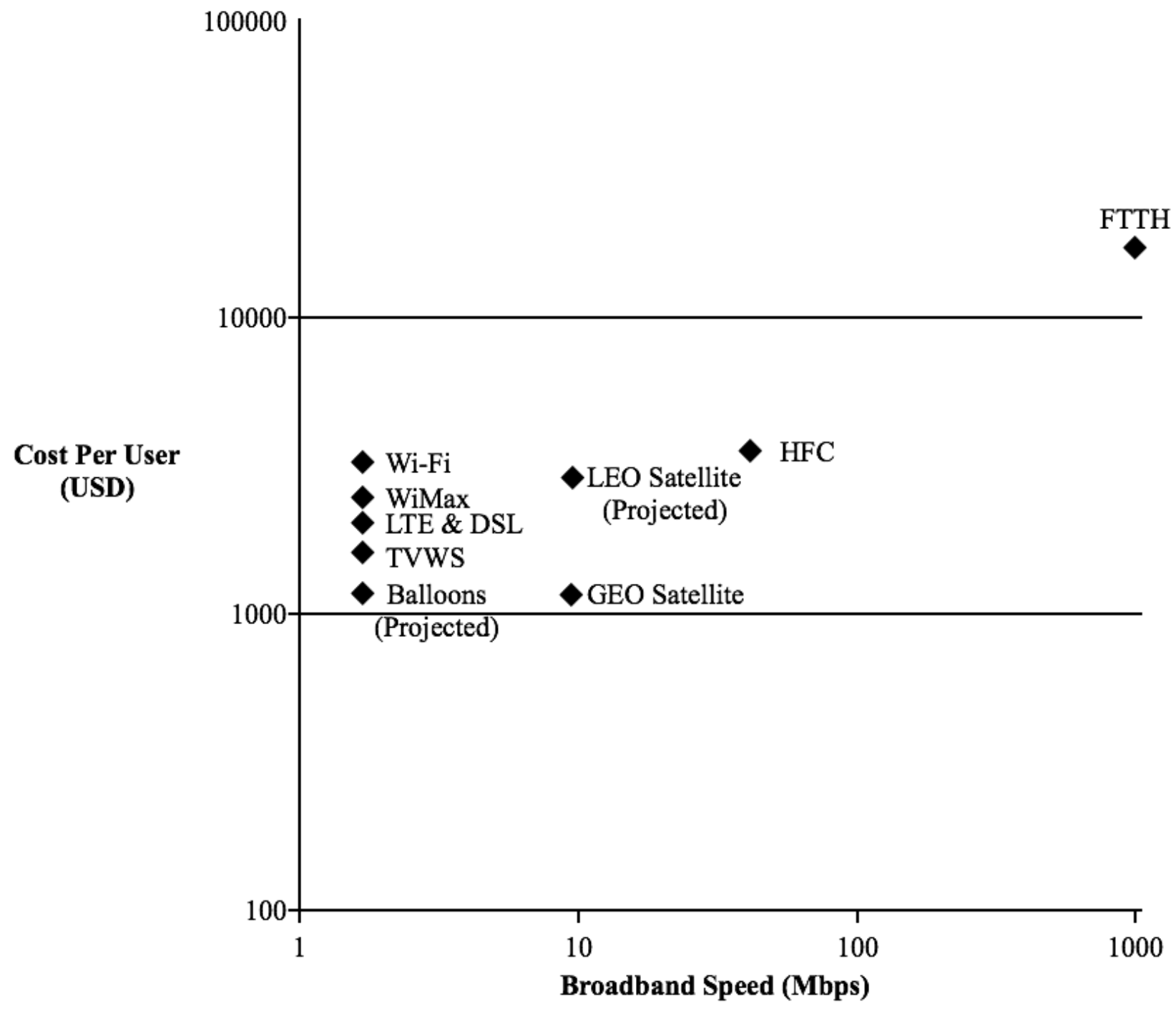

Sources: FTTH: Calix (2010); Cable HFC: Reed (2016); DSL: assumption that rural DSL can provide 2 Mbps broadband service at USD 3000 per user (USD 1500 per Mbps); WiFi/WiMax/LTE/TVWS/Stratospheric: Espinoza (2016); GEO Satellite: FCC (2010); LEO Satellite (projected based on): Boyle (2015) \& de Selding (2016d). 
Figure 5. Comparison of Cost per Mbps versus Speed of Broadband Solutions for Rural Broadband Systems at Low Rates of Adoption (less than 10\%)

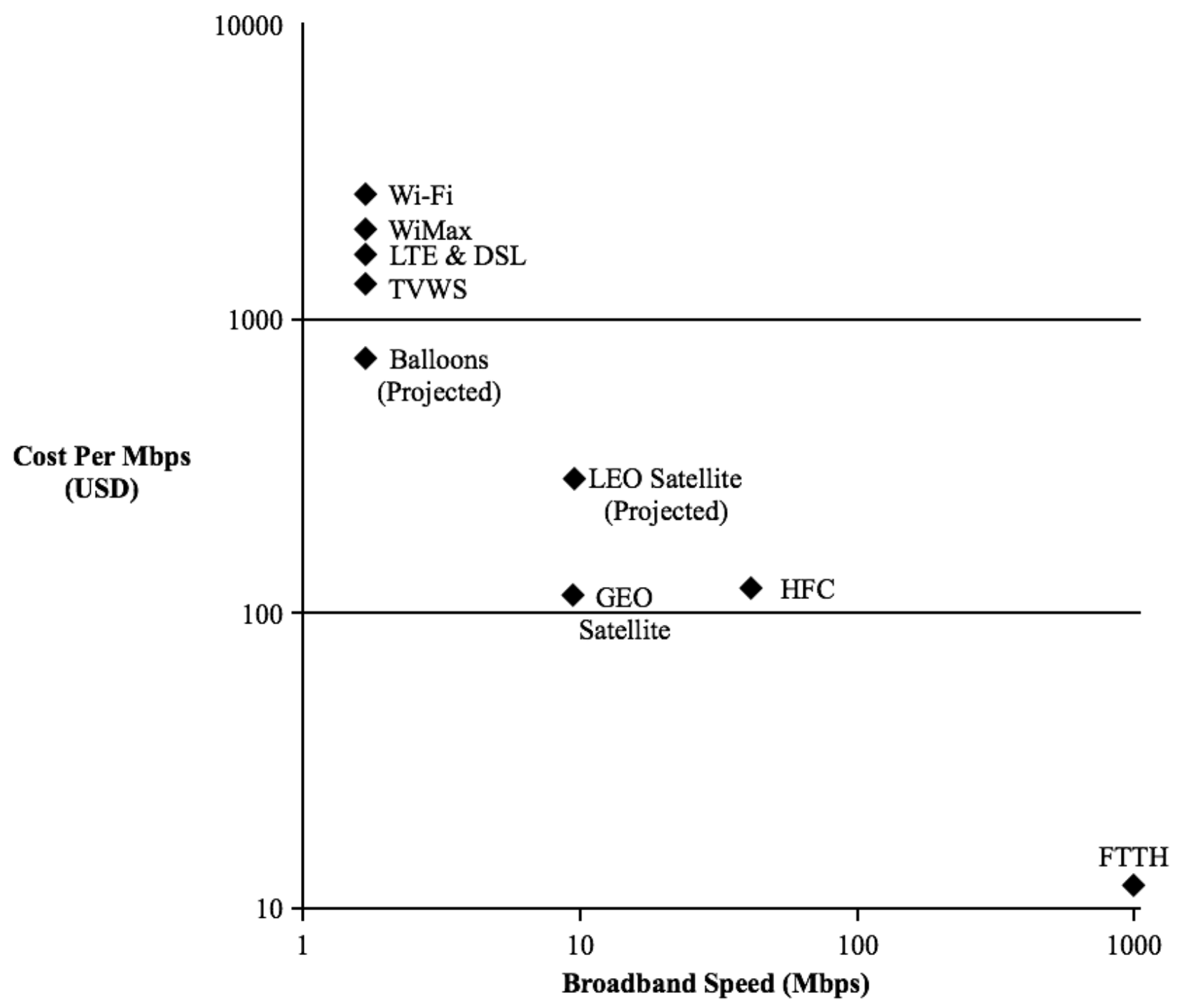

Sources: FTTH: Calix (2010); Cable HFC: Reed (2016); DSL: assumption that rural DSL can provide 2 Mbps broadband service at USD 3000 per user (USD 1500 per Mbps); WiFi/WiMax/LTE/TVWS/Stratospheric: Espinoza (2016); GEO Satellite: FCC (2010); LEO Satellite (projected based on): Boyle (2015) \& de Selding (2016d).

\section{Middle Mile Network Options}

Connecting the network core with the last mile network, there are a limited number of middle mile technology options available and in use today. The main options are the use of a terrestrial fibre optic network, microwave network, or a satellite network. While a detailed analysis of the economic trade-offs between these options is beyond the scope of this report, there are some fundamental observations of middle mile network economics that are relevant to this analysis.

- A terrestrial fibre optic network is often a core component of national broadband plans. These fibre optic networks not only form the basis for the core countrywide backbone network interconnecting to deep-sea intercontinental or international exchanges, but often extend fibre deeper throughout the 
country to serve as middle mile networks as well. As will be discussed later, the presence of a high number of decentralised interconnection points strategically placed throughout a country may have implications for the selection of last mile broadband technologies.

- $\quad$ Often being the lowest cost and easiest to deploy middle mile option, modern digital microwave transmission systems can rival fibre systems in terms of reliability and quality (Cookson, 2013) The most significant limitations for microwave can be the availability of spectrum, the need for line-ofsight connectivity and potentially variable transmission quality due to weather conditions. Nevertheless, it can be an attractive option in areas where there are geographical challenges, where the cost of buried or aerial fibre network installation is very high, or a network connection is needed on a quick turnaround.

- The use of satellites as a middle mile for residential broadband services is not a recent development given the use of the community aggregator model in remote village locations. For many years the most popular transmission architecture in remote villages in the Arctic has been to use wireless or wireline distribution network to the village homes, with this aggregated at a small satellite station in the village for backhaul into the core network. Such solutions have also said to have been used to bring connectivity to communities far from terrestrial infrastructure in the Democratic Republic of the Congo, for example (Hughes, 2016b). New lower-orbit broadband systems, which are, by definition high-throughput, however, are potentially broadening the use of satellites for the middle mile. As discussed earlier in section 2.1.2, O3b Networks has deployed a constellation of 12 MEO satellites to provide middle mile connectivity for MNOs, ISPs or government networks on a global basis between the 45-degree north and south latitudes. Though a highly shared network, the use of broadband satellite technology delivers hundreds of Mbps connectivity on a regional basis. O3b reports that its MEO approach reduces latency to less than $150 \mathrm{~ms}$ allowing for the support of key real-time applications such as VoIP calls and video conferencing.

- $\quad$ New GEO satellite technological capabilities are also driving new middle mile approaches to providing broadband. United States carriers are increasingly using satellite to extend 3G and 4G coverage in underserved areas. For example, they are deploying Very Small Aperture Terminals (VSATs) at towers in some metro edge and rural regions where fixed wireline solutions may not be the most cost effective, or using satellite backhaul as a quickly deployable way to meet periods of high demand, such as for large sporting events.

\section{Role for Satellite}

Given this technical and economic characterisation, what is the best role for using broadband satellites to provide residential broadband service? Based upon the prior characterisation of the economics of local access network alternatives, the role for satellite broadband from GEO satellites appears as an important complementary, or in some cases competitive, technology for providing direct to the home or community aggregator backhaul for residential broadband users living in rural and remote areas beyond the feasible extension of terrestrial networks. There are also promising new opportunities for MEO and LEO satellites both as a middle mile solution to support terrestrial wireless solutions in remote or underserved areas, and as a last mile solution targeting high-speed broadband offerings direct to end users..

What is required for satellites to be a competitive solution for residential broadband service, of course, is the viable delivery of broadband service at speeds and performance levels comparable or better than any other local access network alternatives at competitive prices. For most geographic areas that support dense terrestrial wireline deployments, satellite options will need to provide competitive speeds and prices in order to provide an attractive offering. In lower density, remote or rural areas adjoining major population centres, terrestrial services often offer lower broadband speeds or higher subscription prices, reflecting 
higher costs of deployment. Here, GEO-based satellite broadband has become, in some cases, the sole or one of a few, alternatives for some households and introduces needed competition in other lower density areas where terrestrial technologies have not been deployed extensively. The national broadband plans for Australia, Canada, Mexico, and the United Kingdom reflect this trend (Box 7). Indeed, GEO satellites provide the best DTH solution where there are coverage gaps in the most sparsely populated and isolated geographical areas.

\section{Box 7. Deployment of Broadband Access Technologies in Australia, Canada, Mexico and the United Kingdom}

\section{Australia}

With one of the lowest population densities in the OECD, Australia considered the use of all broadband access technologies to meet the policy objectives set out for its National Broadband Network (NBN). NBN uses a mix of fixed access technologies to connect the $93 \%$ urban majority of the population, fixed terrestrial wireless technologies for the $4 \%$ in closely settled areas outside the urban areas and satellites for the remaining $3 \%$ population. NBN launched two geostationary satellites in 2015 and 2016 to provide broadband access to 400000 homes and businesses in rural and remote Australia. 200000 premises, including homes and businesses, are forecasted to have satellite services by 2020, though if demand exceeds expectations in certain geographical locations, NBN has said it will expand fixed wireless services in these areas to free up satellite capacity for other users. For some people "Sky Muster" represents the first connection of any type, given that prior satellites had exhausted their capacity with no alternative access choice, while for others it represents a large step forward compared to dial-up or $3 G$ wireless technologies. Even though NBN has said it will apply 'cross subsidies' from services offered over other technologies, the higher price for service via satellites compared to terrestrial NBN options are evident (see also Table 1).

\section{Canada}

Xplornet is one of Canada's largest rural-based Internet service providers, serving over 300000 customers (CRTC, 2016:2). Xplornet offers service via both DTH satellite and fixed wireless with the optimal mix depending on population density. Xplornet frequently will build up a concentration of DTH customers in a given rural area such that it warrants building out its terrestrial backhauls and fixed wireless access infrastructure. This business model allows Xplornet to gradually expand its terrestrial footprint, which then frees up satellite capacity that can be redeployed. Overall, satellite services are a relatively small share of the market in Canada. Satellite subscriber data is reported combined with fixed wireless, but the two technologies collectively are $4 \%$ of Canada's 13 million total subscriptions.

\section{Mexico}

México Conectado is a governmental program implemented in co-ordination with state and municipal governments to offer free Internet access in schools, hospitals, universities, governmental offices and parks located in communities where no other telecommunication services are available. México Conectado uses terrestrial and satellite technologies with private and government networks operators (Table 5). MEXSAT, operated by the government, provides satellite capacity along with other domestic and foreign operators. 30\% of the 50000 sites connected over the last 3 years are connected via satellite (SCT, 2016).

Table 5. Technology used in Mexico Conectado

\begin{tabular}{ccccccc} 
Network Type & Communities & Education & Health & Investigation & Government & Public Space \\
\hline Terrestrial & $49 \%$ & $70 \%$ & $30 \%$ & $12 \%$ & $97 \%$ & $100 \%$ \\
Satellite & $50 \%$ & $29 \%$ & $66 \%$ & $16 \%$ & $1 \%$ & $0 \%$ \\
High bandwidth & $1 \%$ & $1 \%$ & $3 \%$ & $72 \%$ & $2 \%$ & $0 \%$
\end{tabular}

United Kingdom

Broadband Delivery UK (BDUK) commissioned seven Test Pilots to evaluate different technical solutions to deliver superfast broadband in UK's most sparsely populated areas. Two of these pilots, Avanti and Satellite Internet have deployed superfast-capable satellite. Satellite Internet provided $40 \mathrm{Mbps}$ to deliver 'village pump' backhaul in remote locations with fixed wireless technology to distribute the superfast capability into the home as well as DTH satellite dishes ensuring coverage was available to every location. Avanti, meanwhile, used its existing wholesale model and commercial partnerships to trial the latest superfast-capable consumer hardware and the sustainability of 
higher speed products, as well as the impact of different marketing approaches.

In the emerging findings BDUK published in 2016, the pilots demonstrated the advantages of satellite technology, in particular the speed and ease of deploying speeds above $24 \mathrm{Mbps}$ to almost any UK property in many instances more cost-effectively than alternative technologies (DCMS, 2016a). BDUK's consumer research also indicated consistently positive feedback from its pilots, including with the satellite projects, although they also confirmed the importance of data volumes and caps, which have a direct impact on the satellite operator's ability to ensure the higher download speeds.

Several proposed LEO satellite constellations are being considered both for their promise of lowercost user devices and lower latency broadband service performance. In short, a LEO satellite service has the promise to compete more directly with terrestrial wireless systems on speed and price than some comparable older GEO systems. However, while the cost of individual small satellites is lower, as well as their associated launch and deployment costs, a large number of satellites would need to be launched for a given LEO constellation to initiate commercial service and achieve a competitive grade of broadband service. The relatively high upfront cost of constructing and deploying a large global LEO system will also require a large number of subscribers, on the order of tens of millions, in order for a given LEO constellation to provide an affordable cost and remain commercially successful. Thus, the coverage gap filled by LEO systems will be strongly linked to system adoption. To the extent that large numbers of users subscribe to the network, then the areas served by the systems will likely grow as costs decline. If user growth is not strong, then the areas covered by LEO systems will be more suited to serving more isolated and remote geographic areas, similar to GEO systems.

Satellite systems are also likely to play a role in providing middle mile solutions to local access networks that are not connected to a national core or backbone network. Remote cities, towns, or villages may have sufficient housing density to support a terrestrial wireless broadband network based upon Wi-Fi, LTE, WiMax, or TVWS technologies. These systems need to connect to a core network to access the global Internet, and satellite systems can serve as a cost-effective backhaul option for this purpose compared to terrestrial fibre or microwave systems. The longer the distance required over land to connect to the core network, the more likely that a satellite solution is the lowest cost option. The large capacity of HTS GEO systems permits a larger number of local networks to interconnect to the satellite network, thus lowering interconnection costs by increased cost sharing. Where an extensive fibre backbone network has been deployed, however, then the cost of fibre- or microwave-based middle mile solution may be more attractive due to the shorter distances required to extend the middle mile network. However, if a country has invested in deploying a fibre backbone network that extends widely across most of its geographical territory, then the cost of a fibre- or microwave-based middle mile solution may be more attractive due to the shorter distances required to extend the middle mile network

Existing and proposed LEO, MEO, and GEO systems operators may view middle mile backhaul as an important revenue opportunity for satellite systems as system capacity increases with the deployment of broadband NGSOs and HTS GEO systems. This can take the form of backhaul for ISPs in remote locations, as well as for backhaul to remote mobile base stations to extend mobile coverage. "Hybrid" terrestrialsatellite solutions are now also becoming available from equipment vendors to simplify the implementation of this approach today (Box 8). For the future, potentially innovative stratospheric solutions could also be considered as they may deploy to provide broadband service to the same markets as many satellite constellations, especially if these solutions prove to be operationally viable and cost effective over the next few years. 


\section{Box 8. Hybrid Satellite and Fixed Wireless Solutions}

A potentially cost-efficient way to improve the responsiveness of Internet connections for people living in rural and remote areas, as well as in emerging markets, is a hybrid broadband solution. Here the downstream connectivity is provided by a high-speed satellite service with the upstream connectivity using an existing fixed or mobile connection. There are also variations on this concept. This is not primarily aimed at areas with little existing terrestrial network access or for those areas that have upgraded such infrastructure to already meet their requirements. Rather a hybrid approach, through satellite and terrestrial networks, may be useful for DTH satellite broadcasters, by enabling them to add broadband access to their services. At the same time, mobile or fixed operators may be able to use satellites for the downlink part of their service to boost broadband speeds and capacity rather than investing in new mobile sites or in upgrading their fixed access network. With this in mind, the European Commission has financed a research project called BATS (Broadband Access via integrated Terrestrial \& Satellite systems) to examine the potential for this approach to support their Digital Agenda. ${ }^{1}$ There are some hybrid solutions available in the market today, such as those provided by Forsway from Sweden and Gilat Satellite Networks from Israel. ${ }^{2}$

Forsway's solution is based on four building blocks:

- A server, placed at the service provider location, acts as a gateway to connect subscribers, the Internet, and the satellite system by routing IP data. This serves to provide security and encryption in order to protect from network invasion and to grant access.

- The satellite's transponder capacity forms a communication channel through which to transmit received signals.

- A regular satellite dish is placed at end users' premises to receive signals. Since the dishes are only oneway (receiving information), the size of the dish is smaller than two-way satellite dishes; 0.7 meters compared to 1.2 meters, respectively. This makes installation simpler, making the overall price of both installation and equipment least expensive than satellite-only options.

- $\quad$ A hybrid broadband modem (ODIN) is also placed at the users' premises, and provides the last link for one-satellite broadband by connecting it with other methods for the return channel. Options include integrating a mobile network interface (3G/GPS USB dongle), dial-up or xDSL, depending on the method used for the return channel by the subscriber. Additionally, the modem has the function to accelerate slow ADSL lines by combining it with the satellite downlink, and is also equipped with a DVB-S2 (Digital Video Broadcast - Satellite $2^{\text {nd }}$ Generation) demodulator and advanced IP optimisation tools. It does not currently contain any caching as it would add extra cost for the modems. Forsway has installed approximately 50000 modems around the world, including providing Internet access to village service centres in India, as well as rural places in Europe and the United States; multicast services to retail stores in South Africa; Internet kiosks in East Africa; and broadband addition to DTH and mobile networks in Nigeria.

Given that satellite capacity is increasing and the demand for broadband connectivity is growing, the hybrid solution is an interesting option. It enhances broadband speeds in some instances, and takes a concrete step towards achieving universal broadband. These kinds of hybrid solutions could also be a part of the forthcoming $5 \mathrm{G}$ development which will support a heterogeneous set of integrated air interfaces: from evolutions in current access schemes to new technologies, encompassing cellular and satellite solutions. ${ }^{3}$

1. For more information regarding the research project see http://www.batsproject.eu/.

2. For more information see www.forsway.com and www.gilat.com/SkyEdge-ll-c-Libra.

3. See $5 G$ PPP, supported by the EU Commission. $5 \mathrm{G}$ Vision. The $5 \mathrm{G}$ Infrastructure Public Private Partnership: the next generation of communication networks and services. See www.5g-ppp.eu.

\section{Developing Policies for Broadband Satellite Systems}

This closing section identifies and discusses some important regulatory decisions related to the deployment of emerging broadband satellite systems. The issues covered include government subsidies for 
satellite broadband, national broadband plans, and other regulatory considerations in enabling deployment of new technologies.

\section{Government Incentives for Broadband Satellite}

Government incentives, including subsidies, for the provision of broadband satellite services to remote areas with low population density are a common component of many national broadband plans. Such incentives can take many different forms depending upon the unique local circumstances and the service speed in each country (Box 9). Some funding opportunities may be specific to satellite technologies and others may have technology-neutral requirements. There are three challenges identified within this report regarding the continued execution of such funding programmes:

- The significant innovation occurring in local access network solutions will require on-going analysis of the comparative costs of the new and emerging solutions. For instance, stratospheric technologies may evolve to become a cost-effective solution for an identifiable coverage gap. Likewise, perhaps LEO and MEO systems will emerge as preferred solutions in specific circumstances.

- Additional complexity to broadband plans might arise from considering the availability of and opportunities associated with new technologies or hybrid terrestrial-satellite solutions. Alternatively, the use of satellites as the middle mile portion of mobile or fixed wireless terrestrial networks might make economic sense in different situations. Due diligence on a larger number of different combinations of new technologies will likely become a more important element of broadband plans.

- The uncertainty associated with the fresh wave of innovation manifested by HTS GEOs, LEO and MEO satellites and stratospheric technologies may create a stronger need for market-based mechanisms, such as auctions, for the selection of providers and technologies in the broadband plans. Such election mechanisms would provide regulators with the most up to date information regarding technology advances as reflected in service provider bids. 


\section{Box 9. Government funding opportunities for satellite broadband}

\section{Providing satellite broadband in the Galicia region of Spain}

Galicia is a region located in northwest Spain characterised by extensive rural areas, a complex geography and a dispersed population residing in more than 30000 populated areas of which over $90 \%$ have fewer than 100 inhabitants. Given the strategic value of access to electronic communications networks, and its impact on growth and innovation in all economic sectors and social and territorial cohesion, public authorities have a crucial role to ensure an equitable access to broadband services. Despite investments aimed at network expansion on basic broadband and NGA infrastructure, there is still a small percentage of the population without access to any broadband networks. For these cases, satellite technology is the preferred option. In this regard, the autonomous government of Galicia invested more than EUR 600000 to establish satellite Internet services in these remote locations. This initiative supported satellite operators, contingent on the provision of broadband service for a year with a minimum speed of $2 \mathrm{Mbps}$. In the period of 2012 - 2014, when the public aid was granted, over 6600 inhabitants were connected via satellite broadband service. The Galician government will continue to provide this aid, in accordance with its Broadband Plan 2020.

\section{The United Kingdom's Better Broadband subsidy scheme}

The UK Government launched a direct subsidy scheme in 2015 to enable homes and businesses in some of the most remote areas of the country to access a subsidised satellite broadband connection if they were unable to access speeds above $2 \mathrm{Mbps}$. The scheme has since been broadened in some areas to include fixed wireless, $4 \mathrm{G}$ and fibre to the premise. On-going publicly and commercially funded rollout of superfast (greater than 24 Mbps) broadband is on track to deliver coverage to 95 percent of the UK by the end of 2017. Thanks to new capacity, satellite broadband has become much faster and least expensive; for example one service offers up to 22 Mbps downlink and 6 Mbps uplink, although some consumers may still experience latency issues. Under the scheme, consumers can check what broadband services are available to them and what their current broadband speed is with simple online tools with postcode searches (DCMC, 2016; BT, 2016). If checks demonstrate a consumer cannot access service greater than 2 Mbps, then they may apply for help via their local participating providers operating in their region to obtain a subsidised broadband service. The satellite offer includes a free satellite dish and installation in most cases. The subsidy will be used to reduce the total cost of installation, activation and hardware by up to GBP 350 (USD 507 PPP).

\section{Canada's Far North government funding}

Access to telecommunications in the Canadian north is challenging given the small population spread over a large land mass. Government programs have funded local ground infrastructure, expansion of terrestrial transport links (fibre, cable or microwave), and on-going leases of satellite capacity. Going forward, key opportunities include building more capacity via terrestrial or HTS, while also improving resiliency by having multiple network paths into each community. The latest federal initiative, as announced in the 2016 Budget involves a CAD 500 million investment over five years to expand broadband to rural and remote communities. While the program has not yet been launched formally, Northern communities are expected to benefit. For example, the Quebec government has announced plans to build an undersea fibre optic network to connect satellite-dependent communities in the northern remote region of the province. The initiative is currently in the design phase, but would potentially entail over $3000 \mathrm{~km}$ of new fibre built around northern Quebec with spurs landing in communities currently dependent on satellite.

\section{The "Connect America Fund" and Satellite Broadband}

The FCC has established the "Connect America Fund" to promote the availability of advanced telecommunications services at reasonable rates to the United States public (FCC, 2016d). The Fund provides support to certain qualifying companies that serve high-cost areas to ensure the residents of these regions have access to reasonably comparable service at similar rates to urban areas. It is funded by contributions from telecommunications service providers based on a percentage of their interstate and international end-user revenues. The FCC has structured an auction process to allocate the Fund to carriers that will deploy broadband in rural areas, establishing technology-neutral requirements which enable satellite providers to bid, provided that they meet certain performance requirements (FCC, 2016e). Specifically, the FCC established several tiers for speed, capacity, and latency, which are structured in a way that would encourage all providers, including satellite, to participate. The FCC recognised that some bidders may not be able to meet previously-adopted minimum latency requirement that $95 \%$ or more of all peak period network round-trip latency are below $100 \mathrm{~ms}$. For example, GEO satellite providers cannot meet that requirement, but may be willing to offer higher speeds. As a result, the FCC concluded that bidders with high latency can bid if: (i) $95 \%$ or more of all peak period measurements of network round-trip latency are at or below 750 milliseconds, and (ii) they provide demonstrations of voice performance. 


\section{Policy and regulatory changes}

In addition to the role of government subsidies, continued efforts are underway in many countries to reduce regulatory hurdles or to encourage the deployment of satellite services and to address new issues that have arisen in the context of ever-evolving and emerging satellite technologies. For example, use of spectrum and orbital resources must be coordinated on a domestic and international basis. This section provides examples of efforts in the context of satellite regulation undertaken by various countries in order to promote new innovations in satellite technology and streamline regulatory processes.

The European Commission has supported the Satellite Broadband for European Regions (SABER) project, in order to better shape policies to include the deployment of satellite as a viable option for broadband access. The EC project is sponsored together with the European Investment Bank, the European Space Agency, Eurisy and the Network of European Regions Using Space Technologies, and is made up of satellite operators, manufacturers and several European regions. ${ }^{17}$ In support of the aim to establish best practices for public procurement for European Union institutions and regional Public Authorities, the consortium has recommended the adoption of a voucher scheme in order to overcome the financial barriers to uptake for remote households.

In Brazil, the geography and current broadband penetration provides a clear opportunity for satellite broadband to provide services to non-urban areas with low population density and a low level of current broadband infrastructure. The Brazilian telecommunications regulator Anatel launched a public bidding for five orbital positions in 2011; Hispasat's Amazonas 3, Eutelsat's 35W, América Móvil's Star One D1 and two other Brazilian satellite landing rights were given authorization for Ka band operation. Subsequent public biddings in 2014 and 2015 granted further Ka band operation authorization, showing the government's actions to provide broadband services and backhaul for mobile networks.

Growth in the Ka band satellite capacity is expected in the next few years in Brazil, aided by gradual expansion of HughesNet Brazil and ISPs using the O3b system as well as the launch of new Brazilian geostationary satellites. Two satellites, Yahsat's Al Yah 3 and the government's Defense and Strategic Communication Geostationary Satellite (SGDC), are scheduled to be launched in 2017. The SGDC is a project of the government: i) to provide a secure and sovereign channel for the communications of the Brazilian Armed Forces, and ii) to offer commercial broadband service to regions not covered by the terrestrial network of the state-owned company, Telebras. In addition, another six satellites with Ka band capability which have been authorised by Anatel between 2011 and 2015 will begin to launch from 2018 . This growth is expected to further expand the Brazilian satellite broadband market and to narrow the connectivity gap between urban and rural areas, which according to national statistics was $63.9 \%$ of urban households and only $21.2 \%$ of rural households in the year 2015 (IBGE, 2016).

Another example can be seen in Egypt's national broadband plan, eMisr which aims to extend broadband services across the country. eMisr has ambitious social targets to connect all governmental institutions, and to provide high-speed access points in remote areas. The country has plans to launch an orbital satellite, Egyptcom, in 2019 for broadband and military uses, which is envisaged to be operative for 15 years. Broadband services over Ka-band satellite are expected to stimulate growth in broadband penetration for low-density areas where deploying terrestrial networks are not considered viable. This project is expected to cost around USD 600 million. Additionally, the Assembly, Integration and Test (AIT) centre for satellites located in New Cairo is currently in progress. The centre deploys the infrastructure needed to promote Egypt's space development. At the access end, satellite modems accompanied by automatically directional antenna over vehicles are manufactured domestically for the delivery of IP and video over satellite links based on the DVBS2 standard, thus lowering the cost of devices and enabling more affordable prices. 
The Mexican government has also recognised the possibility of satellites as a way to meet the country's connectivity needs. Mexico released its Digital Connectivity Program, "Broadband for All” in February 2017, which includes plans to update the country's national satellite policy. The policy is currently under consultation and will promote investment, competition and co-operation between public and private institutions for the development of satellite technologies and applications. The policy will support the government's goal to increase coverage and availability of fixed and mobile telecommunications, to close the digital divide in the country, as well as to increase competition in the sector and to develop national competencies in the industry. In addition to Mexico's satellite policy, the National Development Plan of 2013-2018 also acknowledges the role of satellites to 'democratise' access to telecommunications services. In conjunction, Mexico also transformed its regulatory framework in 2013 through a reform of its Constitution. The reforms covered telecommunications and economic competition policy, and led to the Federal Telecommunications and Broadcasting Law (LFTR), which includes updated legislation on satellites.

With the new LFTR, new orbital slots can be granted without an auction process. This approach enables private operators to develop new space projects, and to seek new orbital resources. However, the Instituto Federal de Telecomunicaciones (IFT) maintains the right to directly assign orbital resources to Federal Public Administration agencies and departments and to guarantee their availability for national and public security, connectivity of public sites, social coverage and other goals under the competence of the Federal Executive at all times.

In Mexico, foreign satellite systems that cover and provide services to the national territory are only required to obtain an authorisation from the IFT; a concession is no longer required. Several satellite operators from the United States and Canada such as Hughes, Intelsat, SES, Telesat, and Inmarsat provide Fixed Satellite Service (FSS), Broadcasting Satellite Service (BSS) and Mobile Satellite Service (MSS) over the Mexican territory (Table 6). The Brazilian satellite operator Brasilsat also provides services to the country. Satélites Mexicanos, S.A. de C.V. (SATMEX) is the leading Mexican operator in FSS. In 2014, the French satellite operator Eutelsat acquired 100\% of SATMEX's shares, following the adoption of the LFTR. While the previous law only allowed a share of $49 \%$ of foreign direct investment in the satellite sector, the revision allows for full foreign ownership which enabled Eutelsat's acquisition of SATMEX.

MEXSAT is the government's satellite system with two satellites in operation, the Bicentenario and the Morelos 3, with the third, Centenario's replacement, in planning. Its objective is to provide service coverage to the public, especially in areas where no other methods of connectivity are available, and to ensure communication for reasons of homeland security. In 2013, the government stipulated that at least $30 \%$ of MEXSAT's capacity would be dedicated to providing coverage to rural communities. Telecomunicaciones de México (TELECOMM), a governmental operator of telegraphic and satellite networks, is the satellite operator of MEXSAT. It consists of a joint Fixed Satellite Service (FSS) and Mobile Satellite Service (MSS) system, with one satellite supporting FSS and two satellites supporting MSS (Table 6).

Table 6. Mexican satellite operators

Satellite Operators

Satelites Mexicanos (SATMEX I EUTELSAT Americas)

QuetzSat

MEXSAT/Telecomunicaciones de Mexico- (TELECOMM)

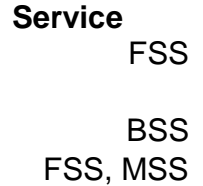

Type

Private

Private

Government 
The United States is also continuing to develop its policies related to satellite communications. In 2015, the FCC approved updates to more than 200 of its rule sections and definitions governing satellite communications. In addition, ongoing efforts are being made to enable spectrum sharing between terrestrial and satellite services, and to better accommodate new satellite technologies such as planned nongeostationary satellite constellations to provide broadband service.

Many new HTS GEO systems either offer or proposing to offer broadband service have been licensed by the FCC, or granted access to the United States market by the FCC. These satellites include, for example, ViaSat-1, ViaSat-2, EchoStar XIX, SES-15, Intelsat 29e, and Intelsat 33e. As noted, satellites such as these that will be deployed or have been deployed into a geostationary-orbit can have a broad coverage area encompassing several countries. In some instances, satellites are licensed by another country, and then subsequently granted market access to provide service in the United States. This also applies to broadband NGSO satellite systems operating in LEO and MEO, which often have global coverage.

Applications seeking to operate NGSO satellites are generally processed alongside other NGSO satellite applications through a separate "processing round" procedure, due to the operational characteristics and spectral needs of NGSO satellite constellations, which are typically different from those of GSO satellites. (FCC, 2003). Recent processing rounds have included applications from NGSO satellite systems seeking to provide broadband service using the Ku-, Ka-, and V-bands. (FCC, 2016a; FCC, 2016b.)

In view of the proposed next generation of large, FSS constellations in low-Earth orbit, the FCC has adopted additional changes to its rules for NGSO FSS systems to facilitate deployment of these systems, which have the capability to provide services, such as Internet access, to under-served communities nationwide (FCC, 2017; FCC, 2016g). The FCC updated certain frequency allocations relevant for FSS systems in the Ka-band, updated criteria to facilitate spectrum sharing among NGSO FSS systems, and amended existing construction milestone and geographic coverage requirements to provide additional regulatory flexibility to operators of NGSO FSS systems.

The policies described in this section represent several approaches to regulation around satellites, and efforts to adapt to new technologies while reducing regulatory hurdles. If the numerous proposed nongeostationary satellite systems are developed as planned, regulatory approaches will continue to need to evolve to accommodate these systems and authorize operations on a timely basis. In addition, national broadband plans, government subsidy programs, and in some cases orbital/spectrum policies will need to be modified to address new technologies and the changing role of satellite in provision of broadband across the globe.

\section{Conclusion}

This report has examined the evolving role of satellites in delivering broadband to rural and remote areas in light of recent innovations in the industry. After analysing a sample of satellite broadband plans from various regions in OECD member and partner countries, prices and start-costs for plans on offer were found to vary greatly between regions. However there were many similarities among the offers, such as the tendency for providers to differentiate their plans based on data allowance, reflecting the bounded number of subscribers that can be handled on a satellite at a given time. This limited capacity is also the reason that many providers establish a Fair Use Policy, in order to manage this scarce resource, and are beginning to design and launch higher capacity satellites. The report goes on to describe key technological advancements in the industry, including the emergence of broadband LEO/MEO satellites, the development of new launch technologies, and the innovation of GEO HTS and their use of spot beams for more efficient reuse of frequency. 
These developments led to the discussion of the changing economics of satellite and its role in the future. While the affordability and therefore the widespread viability of emerging LEO and MEO systems will depend on the customer uptake to decrease the costs of a global constellation, their improvements in performance over their legacy GEO counterparts allow them to compete with terrestrial options. Satellite also has the potential to play a critical role as a middle-mile solution in conjunction with terrestrial options as well as backhaul for terrestrial networks. Governmental policy in a number of countries has acknowledged the role that satellite could play to connect rural and remote areas and many have incorporated subsidies for satellite service in their national broadband plans. Strides have also been made to reduce the regulatory burden on satellite broadband providers and to adopt a technology-neutral approach to policy. The OECD is also examining the role of satellite within the larger context of other options currently being used by countries to provide connectivity to underserved areas in an upcoming report on expanding connectivity in rural and remote areas. 


\section{NOTES}

Canada likely has satellite broadband penetration above 0.1 per 100 inhabitants but disaggregated data is not available (satellite and fixed wireless subscribers are reported on an aggregate basis).

The community aggregator approach can allow for more efficient local communication services as they do not need to be routed to a satellite in orbit. Proponents of this model have also argued service installations and repairs can be more cost-effective as there is less need for a technician to fly in to the community for routine work due to the more centralised equipment (CRTC, 2014). Other examples of this approach where satellite is used as middle mile transport include O3b's service to remote regions in areas around the equator.

Some companies may offer higher speeds for business clients. Hughes, for example, offers a 25 Mbps download service for residential customers, but also has a 50 Mbps download service available for business users.

Some companies may offer higher data allowances. For example, Via Sat's Exede Internet offers a satellite internet package with 150 GB monthly data allowance to residential consumers in certain areas. (Exede 2017).

A few companies had two offers within the same tier that had the same price/GB; in these cases, both offers were included in the analysis.

Please note that for Turkey, the 2014 OECD conversion rate was used as the 2015 rate was not available.

Highly-elliptical orbit (HEO) satellites are in an elongated orbit and may have the ability to provide high latitude and polar coverage.

For further information regarding the Space Norway system, please see the FCC filing at IBFS File No. SAT-LOI-20161115-00111, and for further information regarding the Karousel system, please see the FCC filing at IBFS File No. SAT-LOA-20161115-00113. Both are available at http://licensing.fcc.gov/myibfs.

"CubeSat" is a subset of the category of nanosatellites and picosatellites. Nanosatellites typically have a mass of $1-10 \mathrm{~kg}$ and picosatellites typically have a mass of $0.1-1 \mathrm{~kg}$. The CubeSat is a specific modular design, a miniaturised satellite in the shape of a $10 \mathrm{~cm}$ cube, with a volume of one liter, and a mass of no more than $1.33 \mathrm{~kg}$. Several of these modules can be linked together (ITU, 2014).

The "Kessler syndrome" describes a situation in which debris generates more debris, leading to an everincreasing probability of collision, and the growth of a belt of debris around the Earth (Kessler and CourPalais, 1978).

For further discussion on the uncertainties in the revenue models for satellite and their growth models for the coming years, please see TMF Associates blog article, "The turning point?" by Tim Farrar athttp://tmfassociates.com/blog/2016/11/02/the-turning-point/.

Cost per Mbps is an imprecise metric, as speed will vary based on geography and number of user requesting services simultaneously. The Mbps metric used in the comparison was based on advertised speeds. 
This figure assumes a cost per home passed of USD 1650 for rural areas plus an USD 700 incremental cost to connect each network user.

This figure assumes a cost per home passed of USD 440 for a $550 \mathrm{MHz}$ HFC system carrying two channels of broadband service.

For more information on Google's Project X, see www.x.company and for the technology behind Facebook's Aquila project, see https://www.facebook.com/notes/mark-zuckerberg/the-technology-behindaquila/10153916136506634/.

These cost metrics for broadband service providers should not be confused with consumer costs associated with the provision of residential broadband such as the monthly price of service or the monthly or daily price of service per GB of the data allowance. While costs to the consumer, the latter are not costs to the service provider in the same direct way as defined by the overall network costs or network costs as set by the offered speed of broadband service. Stated differently, while the data allowance will have a bearing on infrastructure cost, the requirements it establishes on network costs is not easy to define since any given data allowance can be achieved with an infinite combination of speed and usage combinations that make it difficult to define a useful cost per GB metric for network infrastructure.

For more information, please see http://www.project-saber.eu/cms/. 


\section{REFERENCES}

Boeing (2017), “The Boeing Company Application”, Application for Satellite Space Station Authorization, FCC IBFS File No. SAT-LOA-20170301-00028, 01 March, 2017, Federal Communications Commission, Washington D.C., http://licensing.fcc.gov/myibfs/.

Boeing (2016a), “The Boeing Company Application”, Application for Satellite Space Station Authorization, FCC IBFS File Nos. SAT-LOA-20160622-00058 and SAT-AMD-20170301-00030, 22 June 2016, Federal Communications Commission, Washington D.C., http://licensing.fcc.gov/myibfs/.

Boeing (2016b), “The Boeing Company Application”, Application for Satellite Space Station Authorization, FCC IBFS File No. SAT-LOA-20161115-00109, FCC IBFS File No. SAT-LOA20161115-00109, 15 November, 2016, Federal Communications Commission, Washington D.C. http://licensing.fcc.gov/myibfs/.

Boeing (2014), “Boeing Stacks Two Satellites to Launch as a Pair”, News Releases, The Boeing Company, http://boeing.mediaroom.com/2014-11-12-Boeing-Stacks-Two-Satellites-to-Launch-as-a-Pair (accessed on 13 September 2016).

Boyle, A. (2015), "How OneWeb’s satellite internet could weather future disasters", NBC News, 16 March 2015, http://www.nbcnews.com/science/space/how-onewebs-satellite-internet-could-weather-futuredisasters-n324606.

BT (2016), Broadband Availability Checker, British Telecom, https://www.dslchecker.bt.com/ (accessed 10 October 2016).

Calix (2010), "Why are you not getting fiber?", Presentation at the National Association of Telecommunications Officers and Advisors conference, Calix Inc., https://www.natoa.org/events/NATOAPresentationCalix.pdf.

Cookson, Clive (2013), "Time is money when it comes to microwaves", The Financial Times, https://www.ft.com/content/2bf37898-b775-11e2-841e-00144feabdc0.

CRTC (2016), “Oral Remarks of Xplornet Communications Inc.”, Transcripts, Hearing 13 April 2016, Canadian Radio-television and Telecommunications Commission, http://www.crtc.gc.ca/eng/transcripts/2016/tt0413.htm.

CRTC (2014), Satellite Inquiry Report, Canadian Radio-television and Telecommunications Commission, Ottawa, http://www.crtc.gc.ca/eng/publications/reports/rp150409/rp150409.pdf.

Department for Culture, Media and Sport (DCMS) (2016a), Emerging findings from the BDUK Market Test Pilots, UK Government Publishing, London, https://www.gov.uk/government/uploads/system/uploads/attachment_data/file/497369/BDUK_Mark et_Test_Pilots_-_Emerging_Findings_Feb_2016.pdf.

Department for Culture, Media and Sport (DCMS) (2016b), "Go Superfast Checker", London, http://gosuperfastchecker.culture.gov.uk/ (accessed on 10 October 2016). 
de Selding, P. (2016a) "SpaceX's Shotwell on Falcon 9 inquiry, discounts for reused rockets and Silicon Valley's test-and-fail ethos”, SpaceNews, 5 October 2016, http://spacenews.com/spacexs-shotwellon-falcon-9-inquiry-discounts-for-reused-rockets-and-silicon-valleys-test-and-fail-ethos/

de Selding, P. (2016b), "ViaSat details \$1.4-billion global Ka-band satellite broadband strategy to oust incumbent players", SpaceNews, 10 February 2016, http://spacenews.com/viasat-details-1-4-billionglobal-ka-band-satellite-broadband-strategy-to-oust-incumbent-players/.

de Selding, P. (2016c), "Satellite builders say customers paralyzed by technology, financial stresses," SpaceNews, 13 October 2016, http://spacenews.com/satellite-builders-say-customers-paralyzed-bytechnology-financial-stresses/.

de Selding, P. (2016d), "One year after kickoff, OneWeb says its 700-satellite constellation is on schedule", Space News, 6 July 2016, http://spacenews.com/one-year-after-kickoff-oneweb-says-its-700satellite-constellation-is-on-schedule/ (accessed on October 2016).

ESA (2015), "Space Situational Awareness", European Space Agency, www.esa.int/Our_Activities/Operations/Space_Situational_Awareness/About_SSA.

Espinoza, D (2016), "Broadband Technology Roadmap for Rural Areas in the Andes and Amazon Regions in Peru”, forthcoming PhD dissertation, December 2016, University of Colorado Boulder.

Europasat (2016a), "About Us", Europasat, https://www.europasat.com/about-us/ (accessed 24 August 2016).

Europasat (2016b), "Satellite Broadband in France, United Kingdom", Europasat, https://www.europasat.com/satellite-broadband-tariffs/france/ (accessed 5 October 2016).

Eutelsat (2016), “VNO”, Eutelsat Broadband, http://eutelsatbroadband.com/products/vno/ (accessed on 15 December 2016).

Exede (2017) Exede Internet, "Excede Freedom Plan”, http://www.exede.com/freedom/ (accessed on 1 June 2017).

FAA (2016), The Annual Compendium of Commercial Space Transportation 2016, Federal Aviation Administration, Washington D.C., www.faa.gov/about/office_org/headquarters_offices/ast/media/2016_Compendium.pdf .

FAA (2015), 2015 Commercial Space Transportation Forecasts, Federal Aviation Administration, Washington https://www.faa.gov/about/office_org/headquarters_offices/ast/media/Commercial_Space_Transport ation Forecasts 2015.pdf.

FCC (2017), "Update to Parts 2 and 25 Concerning Non-Geostationary, Fixed-Satellite Service Systems and Related Matters," Report and Order and Further Notice of Proposed Rulemaking, FCC No. 17122, Federal Communications Commission, Washington, D.C.

FCC (2016a), “2016 Measuring Broadband America Fixed Broadband Report”, Federal Communications Commission, Washington D.C., https://www.fcc.gov/reports-research/reports/measuring-broadbandamerica/measuring-fixed-broadband-report-2016\#block-menu-block-4. 
FCC (2016b), "OneWeb Petition Accepted for Filing", Public Notice, DA 16-804, Federal Communications Commission, Washington D.C., http://licensing.fcc.gov/myibfs/download.do?attachment_key=1143737.

FCC (2016c), "The Boeing Company requests authority to launch and operate a non-geostationary fixed satellite service system operating in low earth orbit in the $37.5-42.5 \mathrm{GHz}$ (space-to-Earth) and the 47.2-50.2 and 50.4-52.4 GHz (Earth-to-space) bands", Application for Satellite Space Station Authorizations, 22 June 2016, Federal Communications Commission, Washington D.C., http://licensing.fcc.gov/myibfs/download.do?attachment key=1140419.

FCC (2016d), "Universal Service", Federal Communications Commission, https://www.fcc.gov/general/universal-service (accessed on 21 September 2016).

FCC (2016e), "Connect America Fund, ETC Annual Reports and Certifications and Rural Broadband Experiments", Report and Order and Further Notice of Proposed Rulemaking, Federal Communications Commission, FCC 16-64, Federal Communications Commission, Washington D.C., https://apps.fcc.gov/edocs_public/attachmatch/FCC-16-64A1.pdf.

FCC (2016f), "Use of Spectrum Bands Above 24 GHz for Mobile Radio Services (Spectrum Frontier)", Report and Order and Further Notice of Proposed Rulemaking, FCC 16-89, Federal Communications Commission, Washington D.C., https://apps.fcc.gov/edocs_public/attachmatch/FCC-16-89A1.pdf.

FCC (2016g), "Update to Parts 2 and 25 Concerning Non-Geostationary, Fixed-Satellite Service Systems and Related Matters", Notice of Proposed Rulemaking, FCC 16-170, Federal Communications Commission, Washington D.C., https://apps.fcc.gov/edocs_public/attachmatch/FCC-16-170A1.pdf.

FCC (2010), "The Broadband Availability Gap", OBI Technical Paper, N. 1, Federal Communications Commission, Washington D.C., https://transition.fcc.gov/national-broadband-plan/broadbandavailability-gap-paper.pdf.

FCC (2003), "Amendment of Commission’s Space Station Licensing Rules and Policies", First Report and Order and Further Notice of Proposed Rulemaking, FCC 03-102, Federal Communications Commission, https://apps.fcc.gov/edocs_public/attachmatch/FCC-03-102A1.pdf.

Foust, J. (2017), “Blue Origin successfully tests New Shepard abort system,” SpaceNews, 5 October 2017, http://spacenews.com/blue-origin-successfully-tests-new-shepard-abort-system/.

Foust, J. (2016a), "Blue Origin flies New Shepard again”, SpaceNews, 19 June 2016, http://spacenews.com/blue-origin-flies-new-shepard-again/

Foust, J. (2016b), “SpaceX Falcon 9 launches Dragon, lands first stage”, SpaceNews, 8 April 2016, http://spacenews.com/spacex-falcon-9-launches-dragon-lands-first-stage/.

Foust, J. (2016c), “How Big is the Market for small launch vehicles?”, SpaceNews, 11 April 2016, www.spacenewsmag.com/feature/how-big-is-the-market-for-small-launch-vehicles/.

Foust, J. (2014), “Small satellites, small launchers, big business?”, The Space Review, 11 August 2014, www.thespacereview.com/article/2577/1.

Galaxy Broadband (2017), Webpage, Daily thresholds on data allowance, http://www.galaxybroadband.ca/res/why-galaxy-2/faq.html 
Henry, C. (2017), "SpaceX demonstrates rocket reusability with SES-10 launch and booster landing", SpaceNews, 30 March 2017, http://spacenews.com/spacex-demonstrates-rocket-reusability-with-ses10-launch-and-booster-landing/.

Hughes (2017), "HughesNet Gen5 Fair Access Policy for the 10 GB, 20 GB, 30 GB and 50 GB Service Plans”, Hughes Network Systems LLC, http://legal.hughesnet.com/FairAccessPolicyGen5.cfm (accessed on 22 May 2017).

Hughes (2016a), "EchoStar XIX/ Jupiter 2 Launch a Success”, Hughes Network Systems LLC, http://www.hughes.com/resources/echostar-xix-jupiter-2-launch-a-success?locale=en (accessed on 8 February 2017).

Hughes (2016b), "Democratic Republic of Congo, Cellular Backhaul over Satellite in Democratic Republic of Congo", Hughes Network Systems LLC, https://www.hughes.com/collaterallibrary/cellular-backhaul-over-satellite-democratic-republic-congo (February 2016).

HughesNet Brasil (2016), "Home”, HughesNet, https://www.hughesnet.com.br/ (accessed on 20 January 2017).

IADC (2016), Inter-Agency Space Debris Coordination Committee Website, Inter-Agency Space Debris Coordination Committee, http://www.iadc-online.org/ (accessed on 12 September 2016).

IADC (1997), "Reorbit Procedure for GEO Preservation", IADC Recommendation, IADC-97-04, InterAgency Space Debris Coordination Committee, Houston, United States, http://www.iadconline.org/Documents/IADC\%20reorbit\%20recommendation199704.pdf.

Instituto Brasileiro de Geografia e Estatística (IBGE) (2016), “Acesso à internet e à televisão e posse de telefone móvel celular para uso pessoal”, IBGE Publishing, Rio de Janeiro, http://biblioteca.ibge.gov.br/visualizacao/livros/liv99054.pdf.

ITU (2014), "Characteristics, definitions and spectrum requirements of nanosatellites and picosatellites, as well as systems composed of such satellites”, Report ITU-R, SA.2312-0 at 3 (2014), International Telecommunications Union, Geneva, https://www.itu.int/dms_pub/itu-r/opb/rep/R-REP-SA.23122014-PDF-E.pdf.

JSAT International (2016), “Space Segment: Types”, JSat International Inc, http://www.jsati.com/whysatellite-how-Spacesegment1.asp (accessed 13 December 2016).

Kessler, D. K. and B. G. Court-Palais (1978), "Collision Frequency of Artificial Satellites: The Creation of a Debris Belt", Journal of Geophysical Research, Vol. 83/6, American Geophysical Union, pp. 2637-2646, Washington D.C., http://onlinelibrary.wiley.com/doi/10.1029/JA083iA06p02637/full.

LeoSat (2016a), "About Us", LeoSat Enterprises, http://leosat.com/about-us/ (accessed 22 September 2016).

LeoSat (2016b), “LeoSat Petition”, Petition for a Declaratory Ruling Granting Access to the U.S. Market, FCC IBFS File No. SAT-LOI-20161115-00112, 15 November 2016, Federal Communications Commission, Washington D.C., http://licensing.fcc.gov/myibfs.

LeoSat (2016c), "Thales Alenia Space Signs Phase B Contract with LeoSat to Develop High-throughput, Low-orbit Satellite Constellation", News, 16 September 2016, LeoSat Enterprises, 
http://leosat.com/news-blogs/thales-alenia-space-signs-phase-b-contract-with-leosat-to-develophigh-throughput-low-orbit-satellite-constellation/(accessed 22 September 2016).

Lutz, E. (2016), "Towards the Terabit/s satellite - interference issues in the user link", International Journal of Satellite Communications and Networking, Vol. 34/4, Wiley \& Sons Inc., pp. 461-482, http://onlinelibrary.wiley.com/doi/10.1002/sat.v34.4/issuetoc.

Masunaga, S. (2016), "SpaceX faces a more crowded rocket launch market, even when it returns to flight", Los Angeles Times, 21 September 2016, www.latimes.com/business/la-fi-spacex-competitors20160914-snap-story.html.

Musey, J. A. (2016), “Should High-throughput satellites really last 15 years?”, SpaceNews, 29 August 2016, www.spacenewsmag.com/commentary/should-high-throughput-satellites-really-last-15-years/.

Netflix (2016), “Internet Connection Speed Recommendations”, The Netflix Help Center, help.netflix.com/en/node/306 (accessed on 9 December 2016).

NightShift (2017), “Go NightShift with your Netflix”, Aterlo Networks, https://www.gonightshift.com/ (accessed 22 May 2017).

OECD (2016a), Space and Innovation, OECD Publishing, Paris, http://dx.doi.org/10.1787/9789264264014-en.

OECD (2016b), OECD Broadband Portal website, OECD, www.oecd.org/sti/broadband/oecdbroadbandportal.htm (accessed 29 September 2016).

OECD (2014), "Intensity: Activities and outputs in the space economy", in The Space Economy at a Glance 2014, OECD Publishing, Paris, http://dx.doi.org/10.1787/9789264217294-en.

Onera (2015), "Onera is preparing Europe’s future in the launching of small satellites", Communique de Presse, 2 December 2015, Onera, http://www.onera.fr/sites/default/files/communique_de_presse/files/CP-VA-ALTAIR-021515va.pdf.

O3b (2016), “Our technology at a glance”, O3b Networks, www.o3bnetworks.com/technology/ (accessed on 17 October 2016).

Peterson, D. (2015) “A disconnect: Money can’t buy you broadband in wealthy exurbs”, Star Tribune, Minneapolis, http://www.startribune.com/a-disconnect-money-can-t-buy-you-broadband-in-wealthyexurbs/336666211/ (accessed 23 May 2017).

Reed, D (2016), “Trends in Cable Network Economics: Implications for the Open Internet”, Paper presented at the Telecommunications Policy Research Conference 44, 29 September to 1 October 2016, Washington D.C., https://papers.ssrn.com/sol3/papers.cfm?abstract_id=2758731.

Rocket Lab (2017), “Electron”, Rocket Lab USA, www.rocketlabusa.com/electron (accessed on 5 May 2017).

Sandvine (2016), 2016 Global Internet Phenomena: Latin America \& North America, Sandvine Intelligent Broadband Networks, Ontario, https://www.sandvine.com/trends/global-internet-phenomena/. 
Secretaría de Comunicaciones y Transportes (SCT) (2016), México Conectado : Programa anual de conectividad, SCT, Mexico City, http://www.mexicoconectado.gob.mx/images/archivos/PAC2016.pdf.

SpaceX (2017), “Space Exploration Holdings Application”, Application for Satellite Space Station Authorization, FCC IBFS File No. SAT-LOA-20170301-00027, 01 March, 2017, Federal Communications Commission, Washington D.C. http://licensing.fcc.gov/myibfs/.

SpaceX (2016), “Space Exploration Holdings Application”, Application for Satellite Space Station Authorization, FCC IBFS File No. SAT-LOA-20161115-00118, 15 November, 2016, Federal Communications Commission, Washington D.C. http://licensing.fcc.gov/myibfs/

Telesat (2017), “Telesat Canada Petition”, Petition for a Declaratory Ruling Granting Access to the U.S. Market, FCC IBFS File No. SAT-LOI-20170301-0002, 01 March 2017, Federal Communications Commission, Washington D.C., http://licensing.fcc.gov/myibfs/.

Telesat (2016a), “Telesat Canada Petition”, Petition for Declaratory Ruling Granting Access to the U.S. Market, FCC IBFS File No. SAT-LOI-20161115-00108, 15 November 2016, Federal Communications Commission, Washington D.C., http://licensing.fcc.gov/myibfs.

Telesat (2016b), "Telesat Procures Two Prototype Satellites for Global Ka-band Low Earth Orbit Constellation", News and Events, 27 April 2016, Telesat, https://www.telesat.com/newsevents/telesat-procures-two-prototype-satellites-global-ka-band-low-earth-orbit-constellation.

Tooway (2016), “Our subscription offers: Our distributors”, Tooway High speed internet, http://www.tooway.com/i-want-to-subscribe/ (accessed on 15 December 2016).

UNGA (2007), Resolution N. 62/217: International Cooperation in the Peaceful Uses of Outer Space, United Nations General Assembly, New York, http://www.unoosa.org/pdf/gares/ARES 62 217E.pdf.

UNOOSA (2010), Space Debris Mitigation Guidelines, United Nations Committee on Peaceful Uses of Outer Space, Vienna, http://www.unoosa.org/pdf/publications/st space 49E.pdf.

ViaSat (2016), "ViaSat Petition”, Petition for a Declaratory Ruling Granting Access to the U.S. Market, FCC IBFS File No. SAT-LOI-20161115-00120, 15 November, 2016, Federal Communications Commission, Washington D.C., http://licensing.fcc.gov/myibfs/.

Vector (2017), "Vector Launch Vehicle Family", Vector Space Systems, https://vectorspacesystems.com/technology/ (accessed on 5 May 2017).

Virgin Galactic (2017), “Welcome, Virgin Orbit!”, Virgin Galactic, 2 March 2017, http://www.virgingalactic.com/welcome-virgin-orbit/.

Warwick, G. (2015), "Emerging Small-Satellite Launch Vehicles", Aviation Week \& Space Technology, 16 December 2015, http://aviationweek.com/space/emerging-small-satellite-launch-vehicles\#slide-0field_images-1389141.

WorldVu Satellites Limited (2017), “OneWeb Petition”, Petition for a Declaratory Ruling Granting Access to the U.S. Market, FCC IBFS File No. SAT-LOI-20170301-00031, 01 March 2017, Federal Communications Commission, Washington D.C., http://licensing.fcc.gov/myibfs/. 
WorldVu Satellites Limited (2016), "OneWeb Petition", Petition for a Declaratory Ruling Granting Access to the U.S. Market, FCC IBFS N. SAT-LOI-20160428-00041, 28 April 2016, Federal Communications Commission, Washington D.C., http://licensing.fcc.gov/myibfs/.

Xplornet Communications (2016a), "Traffic Management Policy - Hughes Ka Platform", Xplornet Communications, www.xplornet.com/legal/usage-traffic-policies/satellite-kah-traffic-managementpolicy (accessed 31 August 2016).

Xplornet Communications (2016b), "Our Internet Packages", Xplornet Communications, https://www.xplornet.com/our-internet-packages/ (accessed 5 October 2016). 